Validación de la técnica análisis de contenido basado en criterios desde las sentencias judiciales proferidas en el circuito de Fusagasugá -Cundinamarca

Ángela Milena Fontecha Bello, Lina María Fonseca Ortiz

Ángela Cristina Tapias Saldaña

Director

Universidad Santo Tomás

Facultad de Psicología

Maestría en Psicología Jurídica

Bogotá, Enero 2014 


\section{VALIDEZ DE LA TÉCNICA ANÁLISIS DE CONTENIDO BASADO EN \\ CRITERIOS 2}

\section{Índice}

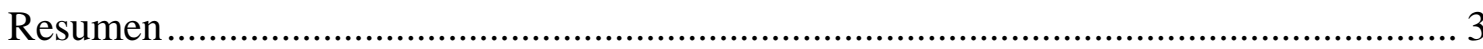

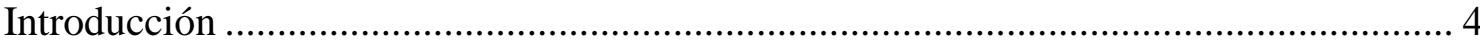

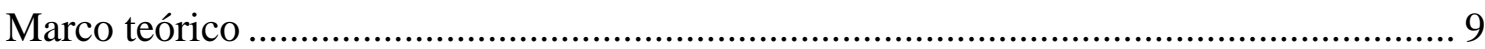

Tipificación del delito sexual en Colombia ...................................................................... 9

El código de procedimiento penal y la prueba testimonial …...........................................13

Psicología forense en el ámbito del delito sexual ............................................................. 16

La entrevista como método de obtención de información .................................................. 19

Análisis de contenido basado en criterios y credibilidad del testimonio infantil .................21

CBCA en el marco jurisprudencial colombiano ................................................................ 23

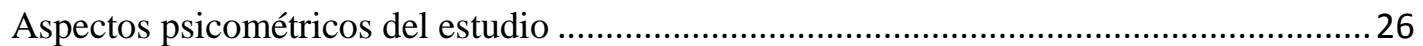

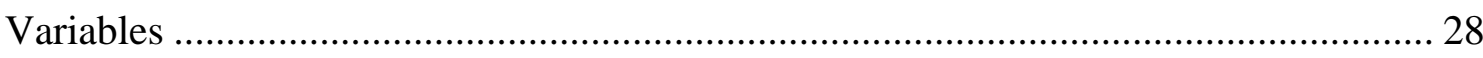

Puntaje obtenido a partir de la aplicación de la técnica CBCA …...........................................28

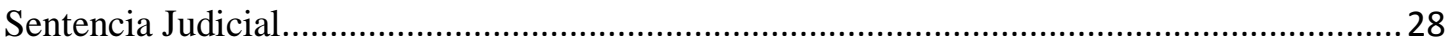

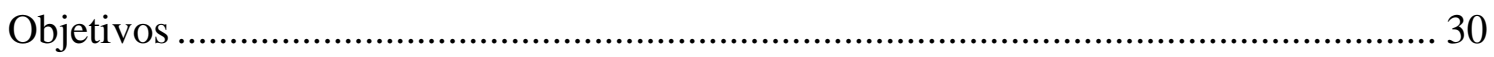

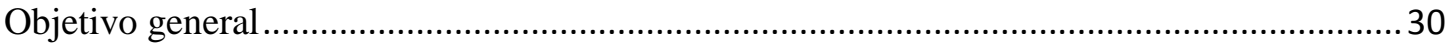

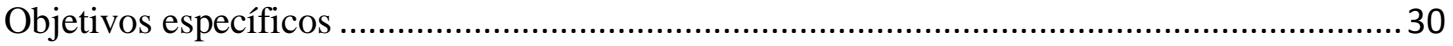

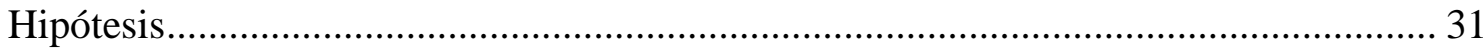

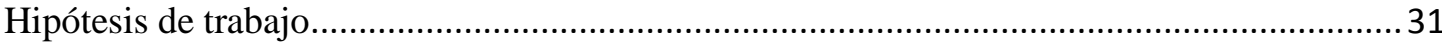

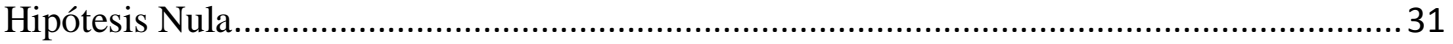

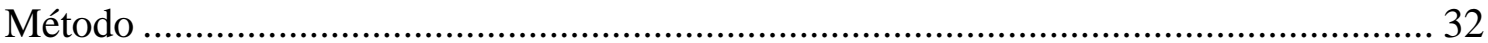

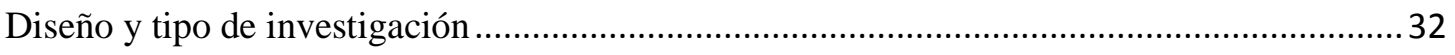

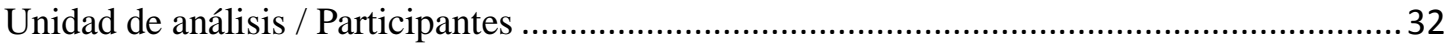

Instrumentos y técnicas de recolección de información ...........................................................33

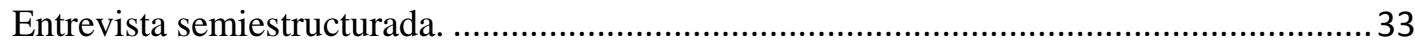

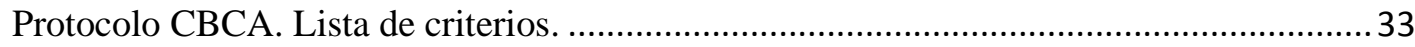

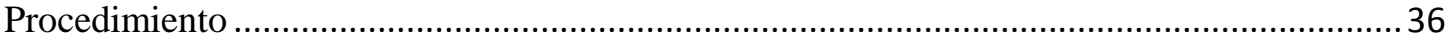

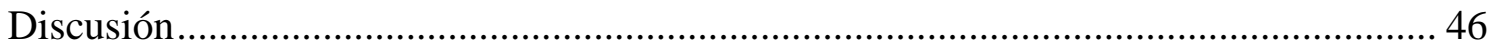

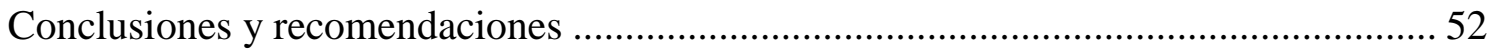

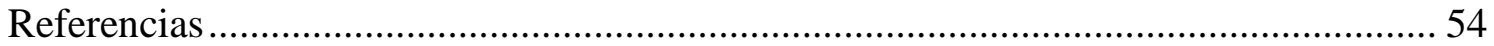

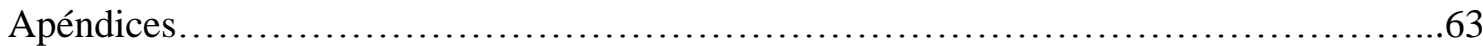




\title{
Validación de la técnica análisis de contenido basado en criterios (CBCA) desde las sentencias judiciales proferidas en el circuito de Fusagasugá
}

\author{
Ángela Milena Fontecha Bello, Lina María Fonseca Ortiz
}

Ángela Cristina Tapias Saldaña ${ }^{1}$

\begin{abstract}
Resumen
En los delitos sexuales en los que las víctimas son menores de edad y en los cuales no es posible encontrar evidencia física de respaldo; la declaración se convierte en la principal prueba de la responsabilidad penal. En virtud de ello, el estudio tuvo como objetivo establecer la validez de la técnica de Análisis de Contenido Basado en Criterios (CBCA), para lo cual, se realizó un estudio instrumental que permitió revisar las propiedades técnicas de la misma. Se empleó una muestra de 8 entrevistas practicadas a niñas (5 a 11 años) víctimas de delitos sexuales judicializados en la Unidad Seccional de Fiscalías de Fusagasugá con sentencias judiciales condenatorias proferidas por este. Los instrumentos empleados fueron la entrevista semiestructurada y el protocolo CBCA. Se estableció la validez de contenido de las operacionalizaciones realizadas a los 19 criterios del CBCA, obteniendo una V Aiken global de 0.83. Asimismo, se obtuvo un nivel de acuerdo entre los jueces para los 19 criterios del CBCA de 75\%; resultando satisfactorios con base en los criterios de concordancia entre jueces para la V de Aiken. Los resultados hallados respaldan el uso de la técnica CBCA.
\end{abstract}

Palabras clave: Análisis de contenido basado en criterios, propiedades técnicas, sentencias judiciales, delitos sexuales, responsabilidad penal.

\begin{abstract}
In sexual offenses where the victims are minors and there is no physical evidence to support, statement becomes the main prove of criminal responsibility. Due to this, the present study pointed out to establish the validity of the Criteria Based Analysis Content (CBCA), for which, an instrumental study that allows checking the technical properties was developed. It was used a sample of 8interviews practiced on girls (5-11 years) victims of sexual offenses prosecuted in the Unit of Prosecutor Office in Fusagasuga with damning judgments handed down by it. It established the content validity of the operationalizations at each of the 19 CBCA criteria, obtaining a global V of Aiken of 0.83 . It was also obtained a level of agreement among the judges of $75 \%$ for the 19 CBCA criteria, resulting satisfactory based on the criteria of agreement between judges for the $\mathrm{V}$ of Aiken. The results support the use of the CBCA technique.
\end{abstract}

Key words: Criteria Based Analysis Content, technical properties, damning judgments, sexual offenses, criminal responsibility.

${ }^{1}$ Directora trabajo de grado 


\section{VALIDEZ DE LA TÉCNICA ANÁLISIS DE CONTENIDO BASADO EN \\ CRITERIOS 4}

\section{Introducción}

Actualmente en Colombia, son muchos los factores de riesgo y problemáticas sociales, políticas, culturales y económicas las que impiden a los niños, niñas y adolescentes desarrollarse integralmente. En este sentido, se hace evidente la importancia de abordar desde una perspectiva transdisciplinar tales condiciones a fin de procurar una vida plena y digna para esta población; así como, para las generaciones futuras de un país considerablemente abatido por problemáticas de carácter desintegrador. Teniendo en cuenta esos factores, el Ministerio de Protección Social (2006), menciona que aun cuando la violencia política ha afectado de manera grave a la población infantil, también, lo ha hecho la violencia cotidiana que ha dejado marcadas huellas en su infancia, coartando su libertad, su participación y libre desarrollo de personalidad.

En este sentido, constituye un ejercicio auto reflexivo para cada uno de los ciudadanos colombianos el cuestionarse acerca de cuántos años de vida saludable han perdido los niños y jóvenes de este país, y de qué manera esta pérdida vital ha trascendido en el desarrollo humano de los colombianos; siendo valioso mencionar que Colombia se constituye como un estado social de derecho (Constitución Política de Colombia, 1991) encargado de luchar por el bienestar de los niños, niñas y adolescentes,

a fin de proveer las condiciones necesarias para llevar una vida digna, teniendo al respeto como uno de sus principios fundamentales sobre el cual habrá de originarse una sociedad equitativa (Ministerio de Protección Social, 2006).

Por lo tanto, se hace pertinente e importante considerar el fenómeno del delito sexual, el cual por sus características de vulneración afecta directamente los procesos de 


\section{VALIDEZ DE LA TÉCNICA ANÁLISIS DE CONTENIDO BASADO EN \\ CRITERIOS 5}

desarrollo y bienestar en una obligación tan sensible como la infanto - juvenil. Según el Instituto Nacional de Medicina Legal y Ciencias Forenses, en el año 2004 se registraron 14.334 dictámenes por delito sexual a menores de 18 años (Ministerio de Protección Social, 2006); sin embargo, estos datos han variado significativamente, encontrando que para el año 2011 se practicaron 22.597 exámenes sexológicos forenses en presuntas víctimas de delitos sexuales de los cuales los niños son la población más vulnerable, encontrando tasas muy superiores en comparación con los adultos en tanto el 94\% de los exámenes en el sexo masculino corresponde a niños y adolescentes, y el $85 \%$ de los exámenes practicados a personas del sexo femenino, a niñas y adolescentes (Vergel, 2011).

Tal como lo presenta el Instituto Nacional de Medicina Legal y Ciencias Forenses -INMLCF- en la descripción epidemiológica de los exámenes sexológicos forenses, y siendo similar a lo ocurrido en los años anteriores al 2011, las mayores tasas para el sexo masculino corresponden al grupo etario de 5 a 9 años con 67 casos por 100.000 habitantes; mientras que, para el sexo femenino, se encuentran en las niñas de 10 a 14 años, con una tasa de 340 casos por 100.000 habitantes.

En consonancia con lo anterior, resulta necesario revisar la legislación interna con el objetivo de tener claridad sobre aquellos comportamientos que son tipificados como delitos sexuales. El abuso sexual se enmarca dentro de los delitos en contra de la libertad, integridad y la formación sexuales descritos en los Artículos 205, 206, 207, 208, 210, 210 A y 212 del Código Penal (CP) Ley 599 de 2000. Sin embargo, se debe recordar que al interior de los delitos sexuales existe un tipo jurídico, que por su naturaleza no deja huella o lesión física en la víctima, derivando en una dificultad 


\section{VALIDEZ DE LA TÉCNICA ANÁLISIS DE CONTENIDO BASADO EN \\ CRITERIOS 6}

manifiesta para su identificación en razón a que, tal vez, el único elemento con que se cuenta para establecer su presentación es la declaración e-dichø del niño o niña que las vivenció. Dichas conductas se encuentran definidas en el Artículo 209 del CP como actos sexuales con menor de 14 años; los cuales, se entienden como: "actos sexuales diversos del acceso carnal [...] o en su presencia, [...] la induzca a prácticas sexuales $[\ldots] "$

Adicional de las conductas antijurídicas citadas, la legislación vigente contempla otros tipos penales, tales como, la explotación sexual, entendiendo está a la luz de la inducción a la prostitución, proxenetismo con menor de edad, constreñimiento a la prostitución, trata de personas, estímulo a la prostitución de menores, demanda de explotación sexual comercial de persona menor de 18 años de edad, pornografía con personas menores de 18 años, turismo sexual, utilización o facilitación de medios de comunicación para ofrecer actividades sexuales con personas menores de 18 años y omisión de (Ley 599 de 2000).

Por ser amplia, compleja y diversa la clasificación de los delitos sexuales, en el presente estudios se incluyeron particularmente los delitos de acceso carnal violento, acto sexual violento, acceso carnal abusivo con menor de catorce años y actos sexuales con menor de catorce años, que fueron puestos en conocimiento de la Unidad Seccional de Fiscalías de Fusagasugá, y cuya indagación e investigación culminó en la etapa de juicio oral, seguida de la correspondiente sentencia proferida por la autoridad judicial competente en primera instancia, tal como, se describe dentro del Código de Procedimiento Penal, Ley 906 de 2006. 


\section{VALIDEZ DE LA TÉCNICA ANÁLISIS DE CONTENIDO BASADO EN \\ CRITERIOS 7}

Dado el creciente interés por comprender el delito sexual dentro del marco jurídico, y de manera particular la importancia de la declaración del testigo infantil como determinante de la responsabilidad penal; desde la psicología como se han desarrollado técnicas, procedimientos y protocolos encaminados a establecer la credibilidad del testimonio infantil a partir del análisis de los factores que interviene en la recuperación o o elaboración de una memoria (Blandon-Gitlin, Pezdek, Lindsay y Hagen, 2008; Pezdek, Morrow, Blandon-Gitlin, Goodman, Quas, Saywitz, Bidrose, Pipe, Rogers y Brodie, 2004); las características de la entrevista, el entrevistador y el niño entrevistado (Cronch, Viljoen, y Hansen, 2006; Geiselman, y Fisher, 1994; Steller y Koehnken, 1994; Vrij, 2000, Vrij, 2005; Vrij y Mann, 2006), la presencia de eventos sugeridos, la motivación para reportar en falso (Blandon-Gitlin, et al 2008), entre otros.

Dentro de los hallazgos y aportes de investigaciones como las citadas, se cuenta actualmente en el contexto de la psicología jurídica con procedimientos fiables para evaluar la madurez cognoscitiva de los testigos infantiles (Tapias, Aguirre, Moncada y Torres, 2004), así como con estrategias que permiten establecer el grado de credibilidad de la declaración de niños, niñas y adolescentes víctimas de abuso sexual; factor particular sobre el que se centró el presente estudio y considerando la aplicación que hoy en día se tiene en el contexto colombiano de la técnica forense conocida como el Análisis de Contenido Basado en Criterios o CBCA, por sus siglas en inglés (Steller y Kohenken, 1982 citado por Tapias et al, 2004; Steller y Koehnken, 1994).

El objetivo de la investigación fue establecer la confiabilidad y validez de la técnica CBCA para la población colombiana, la cual, es ampliamente es ampliamente utilizada a nivel mundial (Vrij, 2000), y avalada por más de 30 treinta años de manejo 


\section{VALIDEZ DE LA TÉCNICA ANÁLISIS DE CONTENIDO BASADO EN \\ CRITERIOS 8}

(Manzanero, 1997 citado por Tapias et al, 2004); en Colombia su aplicación se ha sustentado a la luz de los hallazgos reportados para otras poblaciones.

A partir de los hallazgos de este estudio se pretende que los resultados derivados de esta herramienta sean introducidos como elemento material probatorio que guíe la resolución judicial bajo el principio de la sana crítica y la búsqueda de la verdad, de acuerdo al interés superior por el niño plasmado en la Ley 1098 de 2006. 


\section{VALIDEZ DE LA TÉCNICA ANÁLISIS DE CONTENIDO BASADO EN \\ CRITERIOS 9}

\section{Marco teórico}

\section{Tipificación del delito sexual en Colombia}

El derecho suele entenderse hoy desde la perspectiva del derecho occidental moderno, como las normas de obligatorio cumplimiento, derivadas del Estado. Es por tanto, el factor por el cual el poder se canaliza, se disciplina y se legitima. Por tanto, se compenetra con la ley emanada del poder legislativo del Estado (Escobar-Córdoba, 2008).

De igual forma, el derecho puede entenderse no sólo como conjunto de normas (derecho en sentido objetivo), sino también como facultad de un sujeto (derecho en sentido subjetivo). Aplicada al derecho penal, significa que a) en sentido objetivo es derecho penal el conjunto de normas que regulan el comportamiento humano, y b) en sentido subjetivo es derecho penal la facultad del Estado de dictar y aplicar dichas normas (Mir, 2003).

Por otro lado, Latorre (s.f., citado por Escobar-Córdoba 2008) menciona con respecto al derecho, en un Estado moderno, es, el conjunto de normas de conducta obligatorias establecidas o autorizadas por el Estado mismo y respaldadas por su poder. De esta manera, el derecho penal hace parte del ordenamiento jurídico, integrado por las normas jurídicas reguladoras del poder punitivo del Estado en las que, a fin de tutelar bienes jurídicos, se definen delitos para los cuales se establecen penas y medidas de seguridad (Orts, González, Matallín y Roig, 2007).

Al considerar lo anterior, resulta pertinente discurrir sobre el Código Penal Colombiano Ley 599/2000 y su título IV, el cual, trata sobre los delitos contra la 


\section{VALIDEZ DE LA TÉCNICA ANÁLISIS DE CONTENIDO BASADO EN \\ CRITERIOS 10}

libertad, integridad y formación sexuales, con respecto a los delitos de acceso carnal violento, acto sexual violento, acceso carnal abusivo con menor de catorce años y actos sexuales con menor de catorce años, delitos que se constituyen como el eje central de la presente investigación.

Con relación al acceso carnal violento, en el artículo 205 se enuncia, "el que realice acceso carnal con otra persona mediante violencia, incurrirá en prisión de doce (12) a veinte (20) años”. De igual forma, el artículo 206 refiere sobre el acto sexual violento; "el que realice en otra persona acto sexual diverso al acceso carnal mediante violencia, incurrirá en prisión de ocho (8) a dieciséis (16) años. Por otra parte, en el artículo 208 en cuanto el acceso carnal abusivo con menor de catorce años indica "el que acceda carnalmente a persona menor de catorce (14) años, incurrirá en prisión de doce (12) a veinte (20) años". Por último, el articulo 209 en referencia con los actos sexuales con menor de catorce años, describe "el que realizare actos sexuales diversos del acceso carnal con persona menor de catorce (14) años o en su presencia, o la induzca a prácticas sexuales, incurrirá en prisión de nueve (9) a catorce (14) años”.

Respecto a la tipicidad, tal como, encontraron Barraza, Buenahora, Caicedo, Benjumea y Poveda (2010) en su estudio sobre la jurisprudencia colombiana en casos de delitos sexuales cometidos contra mujeres y niñas, que el delito sexual se ha dividido en tres clases: los de violación, cuyo contenido se circunscribe a los tipos penales que exigen violencia o poner a la víctima en incapacidad de resistir; los abusivos, que son aquellos que se comenten contra menores de 14 años o contra personas que se encuentran en incapacidad de resistir, y finalmente los de proxenetismo, cuyo propósito es la obtención de beneficio económico con la violencia sexual ejercida contra otras 


\section{VALIDEZ DE LA TÉCNICA ANÁLISIS DE CONTENIDO BASADO EN \\ CRITERIOS 11}

personas. En adición, la Corte Constitucional en sentencia C- 674 de 2005 ha reiterado que los tipos relevantes de delitos contra la libertad, integridad y formación sexuales, son tipos de actividad o de mera conducta, lo cual significa que la conducta será punible en razón al comportamiento del agente, independientemente de sus consecuencias (Reyes, 1994 citado por Barraza et al, 2010).

De acuerdo con lo anterior, la disertación entre un tipo penal y otro debe responder a los alcances mismos de la conducta tipificada, notándose que en los articulados referidos como objeto de esta investigación, la acción puede resultar difusa. De esta forma, expresiones como acceso carnal mediante violencia (art.205) o acceso carnal abusivo (art. 208), acto sexual diverso al acceso carnal mediante violencia (art. 206) o actos sexuales diversos del acceso carnal abusivos (art. 209) han sido el punto de partida para diversos pronunciamientos de la judicatura respecto de los factores estructurales de la conducta, ya sea esta denominada acceso carnal o acto sexual.

Si bien a partir del artículo 212 del Código de Penal el acceso carnal se ha entendido como la penetración del miembro viril por vía anal, vaginal u oral, así como, la penetración vaginal o anal o de cualquier otra parte del cuerpo humano con un objeto; la penetración como aspecto diferenciador se ha examinado bajo la óptica de factores como la profundidad de la misma (Sentencia del 17 de septiembre de 2008 de la Corte Suprema de Justicia.); las partes del órgano reproductivo femenino comprometidas (Barraza et al, 2010); los objetos con que se realiza además del miembro viril (Sentencia del 17 de septiembre de 2008 de la Corte Suprema de Justicia; sentencia del 23 de mayo de 2007); la relación mecánica entre penetración y eyaculación (Sentencia del 13 de julio de 2006), y los rastros observables de la acción, esto es la presencia o ausencia de 


\section{VALIDEZ DE LA TÉCNICA ANÁLISIS DE CONTENIDO BASADO EN \\ CRITERIOS 12}

huellas como espermatozoides, fluidos, ADN o lesiones al nivel del himen (Sentencia del 17 de septiembre de 2008; Sentencia T-453 del 2 de mayo de 2005).

De otro lado, los actos sexuales son definidos en términos negativos, haciendo referencia a ellos como todo aquello que no constituye acceso carnal. Así, la Corte Suprema de Justicia en Sentencia del 5 de noviembre de 2008 reiteró que los actos sexuales habrán de definirse en razón a las normas sociales o al grado en el que se involucran las zonas erógenas, haciendo claridad en torno a que no basta con que existan tocamientos en zonas erógenas para determinar que se está ante una conducta de naturaleza sexual; sino que, también es necesario además que haya una intención libidinosa en el autor (Sentencia del 28 de agosto de 2009 citada por Barraza et al, 2010). En conjunción; aclara la Corte lo que se entiende como zona erógena, señalando que es toda parte del cuerpo susceptible de ser lugar de una excitación sexual; esto es, la boca, los genitales, senos, cuello, nalgas, orejas, ombligo (Sentencia del 05 de noviembre de 2008 de la Corte Suprema de Justicia).

Es importante considerar, que no es solo la tipificación como elemento aislado lo que permite la comprensión integral de los delitos sexuales. Ha de tenerse en cuenta el análisis contemporáneo que jurídicamente se hace sobre las circunstancias objetivas y subjetivas del delito, siendo este inherente a la jurisprudencia y a las diferentes posturas que sobre un fenómeno se despliegan. En consecuencia, la valoración de los delitos sexuales dentro del ordenamiento interno ha contado con puntos de debate focalizados en la presunción que protege a los menores de 14 años, la tipicidad, el consentimiento, la violencia, la protección a la dignidad y la vida privada de la víctima, la responsabilidad de los autores, la credibilidad del testimonio, la retractación y las reglas de la 


\section{VALIDEZ DE LA TÉCNICA ANÁLISIS DE CONTENIDO BASADO EN \\ CRITERIOS 13}

experiencia y la sana critica en punto de la valoración de las pruebas (Barraza et al, 2010).

\section{EI Código de Procedimiento Penal y la prueba testimonial}

Tal como se mencionó, el análisis jurídico de los delitos sexuales va más allá de la adecuación típica, siendo entonces necesaria la asunción de un modelo procesal que permita establecer, con respeto al debido proceso y las garantías fundamentales, en qué medida la conducta estudiada resulta lesiva y es atribuible a un ciudadano. Para responder a ello, en Colombia se adopta la Ley 906/2004, por la cual, se expide el Código de Procedimiento Penal, enunciando sus principios rectores y las garantías procesales. En virtud de esto, en su artículo 10 sobre la actuación procesal refiere que, se tendrá en cuenta el respeto a los derechos fundamentales de las personas que intervienen en ella y la necesidad de lograr la eficacia del ejercicio de la justicia, serán de obligatorio cumplimiento los procedimientos orales, la utilización de los medios técnicos pertinentes que los viabilicen y los términos fijados por la ley o el funcionario para cada actuación (Congreso de la República, 2004).

Es precisamente la necesidad de lograr la eficacia del ejercicio de la justicia lo que llevó que en Colombia se pasara de un sistema inquisitivo, caracterizado por la concentración de las funciones de investigar, acusar y juzgar en cabeza de la Fiscalía General de la Nación (Ley 600/ 2000), a un sistema tipo acusatorio, oral y adversarial en el que las funciones de investigar y acusar recaen sobre la Policía Judicial y la Fiscalía General de la Nación, mientras que, la acción de juzgar compete a una tercera instancia imparcial en la que se resolverá y pretenderá llegar a la verdad formal en función a los 


\section{VALIDEZ DE LA TÉCNICA ANÁLISIS DE CONTENIDO BASADO EN \\ CRITERIOS 14}

medios cognoscitivos, esto es, elementos materiales probatorios, la evidencia física y la información legalmente obtenida (Ley 906 del año 2004).

Con el ánimo de comprender la incidencia del testimonio como medio de prueba para llegar a la verdad formal, resulta importante definir esta última en palabras de Plascencia (sf) como aquella que sirve de base para la decisión del juez, como si fuere verdad, aun cuando en rigor no lo sea, toda vez que, la verdad material supondría la reconstrucción de los hechos tal como ocurrieron, situación por demás imposible. Es así, como el conocimiento de la verdad formal se deriva de la dinámica de argumentación y convicción que despliegue cada una de las partes involucradas, requiriéndose de estas que cumplan con los criterios de suficiencia y pertinencia para la explicación del hecho probable (Bedoya y Londoño, 2008).

Es en este punto en el que la Ley 906/2004, en el artículo 382 señala los medios de conocimiento, a través de los cuales se puede llegar al esclarecimiento de un hecho. Los medios de conocimiento a saber son; prueba testimonial, prueba pericial, prueba documental, prueba de inspección, así como, los elementos materiales probatorios, la evidencia física, o cualquier otro medio técnico o científico, que se mantenga dentro del ordenamiento jurídico.

Algunos de los medios de conocimientos que resultan de interés para la presente investigación, son; la prueba pericial y la prueba testimonial. Con respecto a la primera, es procedente cuando sea necesario efectuar valoraciones que requieran conocimientos científicos, técnicos, artísticos o especializados. El servicio de peritos lo realizan expertos de la Policía Judicial, Instituto Nacional de Medicina Legal y Ciencias Forenses, entidades públicas o privadas, y particulares especializados en la materia de 


\section{VALIDEZ DE LA TÉCNICA ANÁLISIS DE CONTENIDO BASADO EN \\ CRITERIOS 15}

que se trate. La prueba pericial debe ser presentada bajo la gravedad del juramento y si el juez admite el informe presentado por el perito, se ordenará su citación para que concurra a la audiencia del juicio oral y público con el fin de adelantar los interrogatorios.

Sin embargo, para apreciar la prueba pericial, en el juicio oral y público, se tendrá en cuenta la idoneidad técnico científica y moral del perito, la claridad y exactitud de las respuestas, el comportamiento al responder, el grado de aceptación de los principios científicos y técnicos en que se apoya, los instrumentos utilizados y la consistencia del conjunto de respuestas. Por lo tanto, para que una opinión pericial referida sea admisible en el juicio, se exigirá como requisito que la base científica o técnica satisfaga al menos uno de los siguientes criterios, a) que la teoría o técnica utilizada haya sido o pueda llegar a ser verificada, b) que haya sido publicada y recibido la crítica de la comunidad académica, c) que cuente con acreditación en el nivel de confiabilidad y 4) que goce de aceptabilidad en la comunidad académica (Ley 906/2004).

Otro medio de conocimiento corresponde a la prueba testimonial, la cual se entiende como; el relato presentado por un tercero ante un juez de conocimiento sobre los hechos o circunstancias relacionadas directa o indirectamente con el delito que se investiga (Martínez, 2006 citado por Bedoya y Londoño, 2008), en lo cual radica la importancia de esta prueba, porque el juez al no haber presenciado lo ocurrido, tiene en los testigos, auxiliares que le dan la posibilidad de tener conocimiento formal del hecho que se investiga (Ellero, 1968, citado por Bedoya y Londoño, 2008). Por lo expuesto anteriormente, el juez tendrá en cuenta los principios técnico - científicos sobre la 


\section{VALIDEZ DE LA TÉCNICA ANÁLISIS DE CONTENIDO BASADO EN \\ CRITERIOS 16}

percepción y la memoria, las circunstancias de lugar, tiempo y modo en que se percibió la situación así como los procesos de recordación, el comportamiento del testigo durante el interrogatorio y el contrainterrogatorio, la forma de sus respuestas y las características de su personalidad.

Adicionalmente, es importante señalar, como la Ley 906/2000 enuncia con respecto a la decisión o sentido del fallo, en el artículo 446; que la decisión será individualizada frente a cada uno de los enjuiciados y cargos contenidos en la acusación, y deberá referirse a las solicitudes hechas en los alegatos finales. El sentido del fallo se dará a conocer de manera oral y pública, y deberá contener el delito por el cual se halla a la persona culpable o inocente.

\section{Psicología forense en el ámbito del delito sexual}

Al conocer las tipificaciones y procedimientos presentados en el Código de Procedimiento Penal sobre estos delitos, resulta pertinente identificar la acción de la disciplina psicológica en el contexto jurídico. Así, se entiende la psicología jurídica como una área aplicada de la psicología científica que se direcciona al análisis e intervención del comportamiento humano que trasciende al ámbito jurídico, enfocando sus hallazgos y aportes a la defensa de los derechos humanos, la salud mental y el impacto de estas en la sociedad, con el fin de alcanza y humanizar la justicia (Tapias y Hernández, 2011)

Si bien el derecho busca regular la conducta, la psicología explica la comisión de la misma, por lo tanto, considerarla como preponderante en la construcción de espacios que permitan generar estrategias de consolidación y materialización de derechos que promuevan la resignificación y dignificación de los niños, niñas y adolescentes, se hace 


\section{VALIDEZ DE LA TÉCNICA ANÁLISIS DE CONTENIDO BASADO EN \\ CRITERIOS 17}

muy importante. Como disciplina integradora, los conocimientos y saberes permiten enriquecer y mejorar la gestión al interior de otras disciplinas, así como el diseño, construcción, consolidación e implementación de programas de prevención y atención, que susciten la defensa, garantía y protección de los derechos (Fonseca, 2012).

De esta manera, se busca una respuesta transdisciplinar a los hechos punibles objeto de esta investigación, a partir del reconocimiento del impacto de la psicología del testimonio, así como, del alcance e incidencia de otras áreas de estudio como el derecho, desde su comprensión y descripción de las conductas típicamente antijurídicas, los procesos de percepción desplegados por los operadores judiciales, las etapas del desarrollo en los procesos nemotécnicos, el aprendizaje, la percepción y la psicología social.

Sabiendo que la psicología no es una disciplina autosuficiente, es preciso mencionar a Vergel (2011), quien señaló que para el año 2011 se practicaron 22.597 exámenes sexológicos forenses en presuntas víctimas de delitos sexuales de los cuales los niños fueron la población más vulnerable. En los delitos sexuales en los que las víctimas son menores de edad, usualmente, ellos son los únicos testigos, además del agresor, convirtiendo su declaración en la principal prueba de la responsabilidad penal, cuando la evidencia física no respalda su declaración. Con relación a lo dicho anteriormente, Jiménez y Martín (2006) consideran que la valoración del testimonio en abuso sexual infantil es uno de los temas más comprometidos en la labor del psicólogo forense. En el caso de la valoración sobre el testimonio de niños, niñas y adolescentes abusados sexualmente, recae una gran responsabilidad sobre el perito, puesto que, se 


\section{VALIDEZ DE LA TÉCNICA ANÁLISIS DE CONTENIDO BASADO EN \\ CRITERIOS 18}

trata, en líneas generales, de episodios ocurridos en la más estricta intimidad, por lo que con frecuencia solo hay dos testigos: el perpetrador y la víctima del mismo.

Lo anterior, sustenta la acción de la disciplina psicológica en el contexto forense, pues, es por medio de técnicas de descripción e identificación de comportamientos como la entrevista, la cual es un elemento material probatorio con vocación testimonial, que tal como lo menciona Franco (2008 citado por Espinosa, 2011), se analiza y evalúa la probabilidad de veracidad en el relato, es decir, se enfoca en la probabilidad de lo creíble de un testimonio. De igual forma, permite la emisión de juicios sobre la credibilidad del testimonio, para lo cual, dispone de recursos logísticos y de un despliegue de protocolos, técnicas e instrumentos de evaluación psicológica. En adición, para Mira (1989, citado por Arce y Fariña, 2005) la estimación de la credibilidad de un testimonio viene a ser la apreciación de la exactitud que el testigo o una parte de su declaración le inspira al evaluador y le induce a creer que los hechos sucedieron tal y como declara.

Tal como se mencionó, dentro de las pruebas periciales que han tomado mayor relevancia en el nuevo sistema acusatorio en materia penal, se encuentra el testimonio, el cual, ha jugado un papel importante durante los procesos judiciales, no solo porque a través de este se introducen al proceso evidencias y elementos materiales probatorios dentro de la dinámica contradictoria del juicio oral (Ley 906/2004), sino porque bajo la calidad de medio cognoscitivo posibilita el acercamiento a la verdad formal en aquellos casos en los que se carece de evidencia física (Escobar y Fontecha, 2005). Por ello, es necesario perfeccionar estrategias que posibiliten la validez de dicho testimonio, puesto que, se asume como prueba fundamental. 


\section{VALIDEZ DE LA TÉCNICA ANÁLISIS DE CONTENIDO BASADO EN \\ CRITERIOS 19}

Los antecedentes de la psicología del testimonio se remontan al origen del derecho. En este sentido, se pueden encontrar referentes sobre la importancia de los testimonios, el procedimiento para su obtención y el papel en la indagación de la verdad en textos griegos y romanos (Foucault, 1983, citado por Manzanero, 2008).

Tal como lo mencionan Escobar y Fontecha (2005), el testimonio puede proporcionar información útil, sin embargo, es necesario comprender y considerar los errores que se pueden presentar en la generación del mismo, por lo tanto y tal como lo presentan Arce y Fariña (2005) el éxito de las herramientas para la obtención de información de los testigos depende de factores como, la pericia del entrevistador, el grado de colaboración del entrevistado, el tiempo transcurrido desde el suceso, y, evidentemente, del tipo de entrevista.

\section{La entrevista como método de obtención de información}

Dentro de la normatividad vigente, la entrevista encuentra sustento en la Ley 906 de 2004 en los artículos 205 en el que se define como una actuación propia de la policía judicial dentro de los denominados actos urgentes; así mismo, el artículo 206 que faculta a los servidores con funciones de Policía Judicial a realizarla cuando se considere fundadamente que una persona fue víctima o testigo presencial de un delito o que tiene alguna información útil para la indagación o investigación. Subsecuentemente el artículo 209 refiere que al estipular la entrevista como una actividad dentro del proceso investigativo, exige el reporte los hallazgos de esta mediante informe escrito; y por último, el artículo 271 abre la puerta para que el imputado o defensor lleve a cabo el procedimiento de entrevista. Bajo cualquiera de las circunstancias en que se adelante, la 
entrevista se efectuará observando las reglas técnicas pertinentes, empleando los medios idóneos para registrar los resultados del acto investigativo (Ley 906/2004).

Con respecto a la metodología para recabar la información, tal como lo presentan León y Alegría (2010), las entrevistas deben tener un orden para permitir la contextualización cronológica de los hechos y con esto establecer lo sucedido. De esta forma, para realizar la entrevista dentro del marco penal se cuenta con pautas estandarizadas para la Policía Judicial, a saber, primero, a) invitar al entrevistado a relatar libremente la información que posea del hecho, y tomar nota que facilite la posterior retroalimentación, b) luego de terminado el relato, se realizarán preguntas concretas que permitan aclarar dudas, plantear y descartar hipótesis, c) solicitar al entrevistado que precise aspectos relevantes de la información que posea sobre el hecho, d) observar y evaluar detalladamente el lenguaje verbal y no verbal del entrevistado, con el fin de obtener indicios sobre la veracidad de la información que suministra (Manual único de Policía Judicial, 2005).

Lo anterior, es especialmente cierto cuando se trata del abordaje de adultos; sin embargo, el Código de Procedimiento Penal Colombiano refiere en el artículo 206 A adicionado por la Ley 1652 de 2013 que, la entrevista forense de niños, niñas o adolescentes víctimas de violencia sexual será realizada por personal del Cuerpo Técnico de Investigación de la Fiscalía General de la Nación, entrenado en dicha técnica, previa revisión del cuestionario por parte del defensor de familia, sin perjuicio de su presencia en la diligencia. En la práctica de la diligencia el menor podrá estar acompañado por su representante legal o por un pariente mayor de edad. Adicional a ello, la entrevista forense debe llevarse a cabo en una cámara de Gesell o en un espacio 
físico dispuesto con los implementos adecuados a la edad y etapa evolutiva de la víctima que permita la grabación en audio o vídeo en su defecto en medio técnico o escrito.

\section{Análisis de contenido basado en criterios y credibilidad del testimonio infantil}

Si bien la legislación nacional ha procurado mejorar la metodología para el abordaje de niños, niñas y adolescentes a partir de algunos referentes teóricos y empíricos, existen aún diversas falencias que dificultan no solo la obtención de información veraz, sino también, controvierten los derechos fundamentales de los menores de edad. De acuerdo con esto, Mapes (1995, citado por Cantón y Cortés, 2007) señala que el evaluador tiene que identificar a todas las personas que hayan hablado con el niño sobre el abuso y comprobar si alguna de estas ha podido influir en la alegación del niño en la reconstrucción del suceso

Para ello, y de acuerdo con Steller y Kohenken (1994), la psicología cuenta con estrategias fiables para evaluar la madurez cognoscitiva de los testigos infantiles y el grado de realidad de su declaración. Dentro de estos se encuentra la técnica denominada Análisis de Contenido Basado en Criterios (CBCA). Así mismo, la psicología forense ha desarrollado al respecto una serie de procedimientos que aportan a la valoración de la fiabilidad y validez del testimonio. Estos se basan en el contenido de las declaraciones que requieren ser obtenidas por uno de los procedimientos previamente revisados. Las grabaciones de las mismas se someten a un análisis de contenido para conocer la validez y observar de ésta, la fiabilidad (Rodríguez, Bringas, Fariña, Arce y Bernardo, 2008). Por lo anterior, se hace importante revisar lo contenido en la literatura sobre el CBCA como instrumento que busca evaluar el grado de credibilidad de los testimonios de niños y niñas víctimas de abuso sexual. 


\section{VALIDEZ DE LA TÉCNICA ANÁLISIS DE CONTENIDO BASADO EN \\ CRITERIOS 22}

El supuesto básico del CBCA es que las declaraciones que se basan en memorias de sucesos reales (auto-experimentados) son diferentes en calidad frente a las declaraciones que no se basan en la experiencia, tal y como ya había puesto de manifiesto Undeutsch (1967, citado en Steller y Boychuk, 1992). Los “criterios de realidad" o "criterios de contenido" reflejan rasgos específicos que diferencian testimonios verdaderos de testimonios inventados. Cada criterio de contenido es un indicador de la veracidad de una declaración, por tanto, su presencia en una declaración dada se contempla como indicador de la veracidad de esa declaración, aunque su ausencia no significa necesariamente que la declaración sea falsa (Manzanero, 2001).

La técnica CBCA tiene en cuenta 19 criterios de contenido enmarcados en cinco categorías: características generales, contenidos específicos de la declaración, peculiaridades del contenido, contenidos relacionados con la motivación, y elementos específicos de la agresión, que van desde lo más general a lo más específico (Manzanero, 2001). En virtud de ello, cabe resaltar como el CBCA es un instrumento que busca evaluar el grado de credibilidad de los testimonios de niños y niñas víctimas de abuso sexual, y tiene su antecedente teórico en las proposiciones de Arne Trankel (1972 citado por Steller y Koehnken, 1994) y en lo que se ha llamado hipótesis de Undeutsch, señalando que las declaraciones correspondientes a eventos experimentados difieren significativamente de aquellas que no tienen un sustento real (Steller y Koehnken, 1994).

Así mismo, Undeutsch enfatizó en la necesidad de evaluar los criterios diferenciales junto con otros aspectos paralelos a fin de hacerse una opinión final en relación con la veracidad de la declaración (Vrij, 2005). Por su parte, Kohnken y Steller 
llevaron el análisis de validez un paso más lejos redefiniendo los criterios propuestos por Undeutsch e integrándolos en un procedimiento formal de evaluación que en la actualidad se conoce como Análisis de Validez de la Declaración (Statement Validity Assesment - SVA) el cual, consta de tres elementos, la entrevista semiestructurada, el análisis a partir de los 19 criterios de realidad que dan forma al CBCA y la evaluación de los resultados del CBCA (Kohnken y Steller, 1994; Vrij, 2000; Vrij, 2005).

\section{CBCA en el marco jurisprudencial colombiano}

Garrido y Masip (1998 citados en Tapias, Aguirre, Moncada y Torres, 2004) refieren que la aceptación de la técnica CBCA por parte de la comunidad académica permitió el conocimiento del modelo a nivel internacional, acompañado de una gran actividad empírica. Hasta el momento, el CBCA se ha investigado en Alemania, Canadá, Estados Unidos, Finlandia, Holanda, Israel y España. Asimismo, mencionan como la técnica CBCA ha sido objeto de la mayor parte de la investigación y es la única técnica que permite evaluar la credibilidad de un relato de una forma relativamente válida. Sin embargo, según Godoy-Cervera e Higueras (2005) el CBCA aún dista mucho de ser una herramienta completamente eficaz en la detección de testimonios engañosos y aún queda mucho por refinar, pues, existen muchos factores que influyen de forma negativa y que pueden modificar sus resultados.

En el mismo sentido, estudios demuestran que las declaraciones veraces contienen un mayor número de criterios frente a las declaraciones fabricadas, sin embargo, la principal y mayor desventaja del CBCA es que no existe un consenso general que establezca un número mínimo de criterios que deba incluir una declaración 
para ser catalogada como creíble, y cuál es el peso que cada uno de ellos debe recibir (Godoy-Cervera e Higueras, 2005).

Si bien, la técnica CBCA es probablemente el instrumento de evaluación verbal más empleado en diferentes estrados judiciales a nivel mundial (Vrij, 2000), y su validez está avalada por más de treinta años de utilización (Manzanero, 1997 citado por Tapias et al, 2004); en Colombia su aplicación se ha procurado y sustentado a la luz de los hallazgos reportados para otras poblaciones (Blandon-Gitlin, Pezdek, Lindsay y Hagen, 2008; Godert, Gamer, Rill, y Vossel, 2005; Vrij, 2000; Vrij, 2005; Vrij y Mann, 2006). De acuerdo con lo anterior, a la fecha, no existe respaldo empírico alguno que permita demostrar su validez científica para la población colombiana, toda vez que, de acuerdo con el único estudio desarrollado en esta dirección concluyó que existe un grado significativo de subjetividad de la técnica, situación que se explica por la ausencia de una definición clara y unificada de los criterios que la componen; así como, de la forma en que debe calificarse cada uno de ellos (Tapias, et al, 2004).

Es precisamente sobre estas investigaciones precedentes que la Corte Suprema de Justicia ha sustentado su posición respecto del uso de la técnica en el contexto colombiano. Particularmente, en la Sentencia 34434 del 09 de Diciembre de 2010, entiende la Corte que existen muchos factores que influyen de forma negativa y que pueden modificar los resultados arrojados por la técnica, razón por la que la alta instancia cita y ratifica lo descrito por Santtila (2000) referido en la Sentencia 34434 del 09 de Diciembre de 2010, al mencionar que el CBCA debe considerarse exclusivamente como un instrumento de apoyo y nunca como herramienta única sobre la cual se base la toma de decisiones judiciales. 
En esta misma sentencia, la Corte pone de presente que el mayor inconveniente de la técnica radica en el carácter subjetivo de la decisión final y la interpretación diferencial que se puede dar a cada uno de los criterios que conforma la técnica; situación que requiere la consideración de otras pruebas como son el peritaje médicoforense, la declaración de testigos oculares, la confesión o allanamiento a cargos, entre otros.

En efecto, el estudio realizado por Tapias, et al. (2004) no solo encontró un factor altamente subjetivo en la técnica CBCA, también, halló que la consistencia interna es tan baja que permite afirmar que los criterios no tienen relaciones internas que faciliten su agrupación en categorías específicas; hallazgo que contradice lo citado en la literatura sobre la asociación de los 19 criterios en 5 categorías. Aun cuando lo descrito a partir del estudio de Tapias et al. (2004) presentó un panorama desolador para la utilización de la técnica CBCA en el contexto de la psicología forense nacional, a raíz de ello, se identificaron debilidades y nuevas líneas de trabajo, las cuales, se abordaron en esta investigación, logrando subsanar los factores que se mostraron como fuentes de error en aquella primera aproximación a la validación del CBCA para población colombiana.

Fue así como el presente estudio empleó el concepto de tres calificadores entrenados en la técnica, y se procuró la minimización del efecto subjetivo inter evaluador al otorgar las calificaciones de los 19 criterios en razón a su presencia o ausencia a partir del relato dado por las niñas previa operacionalización de los criterios desde los referentes teóricos. Adicionalmente, se reafirmó la validez del CBCA a través 
de un criterio externo empíricamente poco empleado (Akehurst, Manton y Quandte, 2011), la sentencia judicial.

\section{Aspectos psicométricos del estudio}

A fin de contextualizar el trabajo realizado desde el campo de la psicometría, es oportuno referir como la formación de juicios legales y la subsecuente exposición de los mismos en sentencias judiciales, que constituyen en factor central del Sistema Judicial (Sallmann y Willis, 1984, citados por Arce y Fariña, 2005), descansan en las dos dimensiones básicas formuladas por los Modelos de Integración de la Información: la fiabilidad y la validez (Ostrom, Werner y Saks, 1978, citados por Arce y Fariña, 2005). Posteriormente, la revisión y puesta en común de la literatura sobre el análisis de contenido de las declaraciones ha llevado al Sistema de Evaluación Global a fraccionar la estimación de la credibilidad de las declaraciones de los testigos en función de estos dos parámetros, la validez y la fiabilidad. Por consiguiente, la validez sirve para establecer la admisibilidad de la prueba para el análisis de contenido, en tanto la fiabilidad se relaciona con los indicios de realidad (Arce y Fariña, 2005).

Para ello, se consideró lo expuesto por Carretero-Dios y Pérez (2007) al mencionar que los psicólogos trabajan con fenómenos no directamente observables, los cuales, pretenden medirse, y para lo que se usan aproximaciones indirectas. De esta forma, su medición está condicionada a la obtención de indicadores observables, y es aquí donde cabría resaltar la importancia de las respuestas generadas ante un test como material esencial para los psicólogos.

Dichas respuestas sirven para generar puntuaciones que finalmente se utilizan con múltiples objetivos, entre ellos, la puesta a prueba de teorías, la toma de decisiones 
acerca de la efectividad de un tratamiento psicológico, entre otros. Las puntuaciones que se obtienen a partir de los tests tienen implicaciones de suma importancia sobre el resultado final de cualquier investigación que haga uso de ellos, al igual que, sobre las consecuencias aplicadas que se derivan de la actividad de los profesionales, y que en su día a día toman decisiones en función del resultado generado por dichos tests (Padilla, Gómez, Hidalgo y Muñiz, 2006, 2007, citados por Carretero-Dios y Pérez, 2007).

En concordancia con lo anterior, el presente estudio permitió establecer la confiabilidad y validez de la técnica análisis de contenido basado en criterios CBCA con base en el análisis de testimonios de niñas víctimas de delitos sexuales cuyos agresores presentan sentencia judicial condenatoria proferidas por el juez de conocimiento de primera instancia del circuito de Fusagasugá. Dicha selección de la muestra se efectuó en razón al control previo sobre el procedimiento de entrevista y recolección de información, identificando una compatibilidad entre las características de esas entrevistas judiciales y la estrategia de entrevista semiestructurada, cuyo punto central fue la narrativa libre. 


\section{Variables}

Teniendo en cuenta que la presente investigación se desarrolló bajo un enfoque cuantitativo, las variables que se tuvieron en cuenta fueron a) el puntaje obtenido a partir de la aplicación de la técnica CBCA a las narraciones suministradas por las niñas ante la Unidad de Fiscalías Seccionales del municipio de Fusagasugá y b) la sentencia judicial proferida por el juez de conocimiento de primera instancia.

\section{Puntaje obtenido a partir de la aplicación de la técnica CBCA}

Dentro del marco de la presente investigación, esta variable de carácter ordinal se entendió como la sumatoria de la asignación numérica otorgada a cada uno de los 19 criterios de realidad que conforman la técnica CBCA, luego de efectuar el análisis verbal a la transcripción de la entrevista suministrada por la víctima; asignando la calificación da cada criterio en razón a su presencia 1 o ausencia 0 dentro del relato. De esta manera, los puntajes totales oscilaron entre 0 y 19.

\section{Sentencia Judicial}

Se entiende como la decisión adoptada por un juez de conocimiento, en primera instancia, luego de haberse surtido la etapa de indagación y de juicio oral; etapa última que culmina con los alegatos de conclusión presentados por las partes intervinientes según se describe en el Capítulo IV de la Ley 906 de 2004. Es precisamente después de este debate final cuando la sentencia judicial, según es descrita para este estudio, tiene lugar. En concordancia con el artículo 445 del Código de Procedimiento Penal Colombiano (Ley 906 de 2004); “Una vez presentados los alegatos, el juez declarará que 
el debate ha terminado y, de ser necesario, podrá decretar un receso hasta por 2 horas para anunciar el sentido del fallo”.

Para los intereses de la presente investigación, esta variable se tomó como una variable nominal medida en razón al sentido de fallo que promulga el juez de conocimiento luego de culminar con la etapa de juicio oral dentro del sistema de responsabilidad penal. De acuerdo con esto, y entendiendo que las sentencias emanadas por autoridad judicial solo pueden ser absolutorias o condenatorias; para los propósitos de esta investigación sólo se incluirán los casos en los que el sentido del fallo proferido es condenatorio, es decir, esta variable da información sobre el criterio de inclusión. 


\section{VALIDEZ DE LA TÉCNICA ANÁLISIS DE CONTENIDO BASADO EN \\ CRITERIOS 30}

\section{Objetivos}

\section{Objetivo general}

Estimar la confiabilidad y la validez de la técnica análisis de contenido basado en criterios (CBCA) a partir del análisis del testimonio de niños, niñas y adolescentes víctimas de delitos sexuales cuyos agresores presentan sentencia condenatoria por el juez de conocimiento de primera instancia.

\section{Objetivos específicos}

1. Estimar la validez de contenido de las definiciones operacionales de los criterios de la técnica CBCA para población colombiana.

2. Estimar la confiabilidad inter-jueces en los criterios de la técnica CBCA aplicada a testimonios en casos de delitos sexuales a niños, niñas y adolescentes en el municipio de Fusagasugá.

3. Describir la credibilidad del testimonio en casos de delitos sexuales a niños, niñas y adolescentes en el municipio de Fusagasugá.

4. Contrastar los referentes conceptuales de la credibilidad del CBCA contra datos empíricos obtenidos en testimonios en casos de delitos sexuales a niños, niñas y adolescentes en el municipio de Fusagasugá. 


\section{VALIDEZ DE LA TÉCNICA ANÁLISIS DE CONTENIDO BASADO EN \\ CRITERIOS 31}

\section{Hipótesis}

\section{Hipótesis de trabajo}

La técnica CBCA cuenta con confiabilidad y validez para establecer la credibilidad del testimonio en niños, niñas y adolescentes víctimas de delitos sexuales, cuyos agresores presentan sentencia judicial condenatoria en primera instancia proferida por el juez de conocimiento del Circuito de Fusagasugá.

Hi: $\mathrm{R}_{\mathrm{ab}} \neq 0$

\section{Hipótesis Nula}

La técnica CBCA no cuenta con confiabilidad y validez para establecer la credibilidad del testimonio en niños, niñas y adolescentes víctimas de delitos sexuales, cuyos agresores presentan sentencia judicial condenatoria en primera instancia proferida por el juez de conocimiento del Circuito de Fusagasugá.

Ho: $\mathrm{R}_{\mathrm{ab}}=0$ 


\section{Método}

\section{Diseño y tipo de investigación}

A fin de responder a la pregunta de investigación se empleó un estudio de tipo instrumental, el cual, según Montero y León (2007) se encamina al desarrollo de pruebas y aparatos, incluyendo tanto el diseño (o adaptación) como el estudio de las propiedades psicométricas de los mismos. Lo anterior, con el fin de estimar la validez de criterio de la técnica CBCA por medio de los análisis del testimonio de niñas referidas como víctimas de delitos sexuales, cuyos agresores presentan sentencia judicial condenatoria en primera instancia proferida por el juez de conocimiento del Circuito de Fusagasugá.

\section{Unidad de análisis / Participantes}

La unidad de análisis son 8 entrevistas de niñas entre 5 y 11 años (media 8,35 años SD 1,92), referidos mediante denuncia formal o de oficio, como víctimas de delitos sexuales ante la unidad seccional de Fiscalías del municipio de Fusagasugá, cuyo proceso ya ha tenido una sentencia judicial condenatoria. Adicionalmente, dichas entrevistas fueron seleccionadas en razón a que su procedimiento habría sido controlado y desarrollado bajo los parámetros de una entrevista semi-estructurada, siendo la narrativa libre el elemento fundamental para la aplicación de la técnica CBCA. En este sentido, se empleó un muestreo no probabilístico, puesto que, la unidad de análisis se seleccionó en función de dos condiciones particulares: la etapa del proceso penal en la que se encontraba el caso del cual iba a ser tomada la entrevista para transcribir y la 
facilidad para acceder a la documentación audiovisual de la entrevista semiestructurada obtenida en la etapa de indagación o investigación.

\section{Instrumentos y técnicas de recolección de información}

\section{Entrevista semiestructurada.}

Dentro del contexto de la investigación forense de los delitos sexuales con victimas menores de edad, la entrevista semiestructurada se define como un procedimiento de recolección de información flexible y adecuado a las necesidades y características del entrevistado, mediante la cual, se permite al niño, niña o adolescente proveer su perspectiva de los hechos que se indagan; modulando la intervención del entrevistador, quien debe limitar sus preguntas con el fin de minimizar los efectos sugestivos de preguntas directas, cerradas, sesgadas, sugestivas o que introduzcan información no revelada por el menor (Arce, y Fariña, 2005; Godoy-Cervera, e Higueras, 2005; International criminal investigative training assistance program ICITAP 2008,2009 y 2011; Raskin y Esplin, 1991 y Vrij, 2005 ).

\section{Protocolo CBCA. Lista de criterios.}

Con el propósito de analizar las entrevistas a partir de la técnica CBCA, se empleó la siguiente matriz en la cual se registraron las puntuaciones otorgadas por los tres jueces evaluadores en cada uno de los 19 criterios propuestos teóricamente por Steller y Kohnken (1994). (Tabla 1). 


\section{Tabla 1}

Protocolo CBCA. Lista de Criterios

\begin{tabular}{|c|c|c|c|}
\hline MATRIZ No. 1 & $\begin{array}{l}\text { Ausente } \\
0\end{array}$ & $\begin{array}{c}\text { Presente } \\
1\end{array}$ & OBSERVACIONES \\
\hline \multicolumn{3}{|l|}{ Características Generales } & \\
\hline \multicolumn{3}{|l|}{ Estructura lógica } & \\
\hline \multicolumn{3}{|l|}{$\begin{array}{l}\text { Elaboración inestructurada (No } \\
\text { Orden Cronológico) }\end{array}$} & \\
\hline \multicolumn{3}{|l|}{ Cantidad de detalles } & \\
\hline \multicolumn{3}{|l|}{ Contenidos específicos } & \\
\hline \multicolumn{3}{|l|}{ Engranaje tiempo espacio } & \\
\hline \multicolumn{3}{|l|}{ Descripción interacciones } & \\
\hline \multicolumn{3}{|l|}{ Reproducción de conversaciones } & \\
\hline \multicolumn{3}{|l|}{ Complicaciones inesperadas } & \\
\hline \multicolumn{3}{|l|}{ Peculiaridades del contenido } & \\
\hline \multicolumn{3}{|l|}{ Detalles inusuales } & \\
\hline \multicolumn{3}{|l|}{ detalles superfluos } & \\
\hline \multicolumn{3}{|l|}{$\begin{array}{l}\text { Incomprensión de detalles relatados } \\
\text { con precisión }\end{array}$} & \\
\hline \multicolumn{3}{|l|}{ Asociaciones externas relacionadas } & \\
\hline \multicolumn{3}{|l|}{ Relatos del estado mental subjetivo } & \\
\hline \multicolumn{3}{|l|}{$\begin{array}{l}\text { Atribución del estado mental del } \\
\text { autor }\end{array}$} & \\
\hline \multicolumn{3}{|l|}{$\begin{array}{c}\text { Contenidos referentes a la } \\
\text { motivación }\end{array}$} & \\
\hline \multicolumn{3}{|l|}{ Correcciones espontáneas } & \\
\hline \multicolumn{3}{|l|}{ Admisión de falta de memoria } & \\
\hline \multicolumn{3}{|l|}{ Dudas sobre el propio testimonio } & \\
\hline \multicolumn{3}{|l|}{ Auto desaprobación } & \\
\hline \multicolumn{3}{|l|}{ Perdón al agresor } & \\
\hline \multicolumn{3}{|l|}{$\begin{array}{c}\text { Elementos específicos de la } \\
\text { agresión }\end{array}$} & \\
\hline \multirow[t]{2}{*}{ Detalles característicos de la ofensa } & & & \\
\hline & & & $0-19$ \\
\hline
\end{tabular}




\section{VALIDEZ DE LA TÉCNICA ANÁLISIS DE CONTENIDO BASADO EN \\ CRITERIOS 35}

Una vez calificadas las entrevistas y obtenido el puntaje total dado por cada uno de los jueces evaluadores entrenados, se registró la información general de las variables, a partir de la cual se desarrolló el análisis (Tabla 2).

\section{Tabla 2}

Matriz de registro de resultados del CBCA

\begin{tabular}{|l|l|l|l|l|l|l|l|l|l|l|l|l|l|l|l|}
\hline PARTICIPANTE & TIPO & & & & & & & & & & & & \\
\\
\hline
\end{tabular}

Es importante aclarar que, para efectos de análisis e interpretación de resultados, la unidad de análisis (entrevistas) se dividirá en dos categorías según la tipología penal. De esta manera, en la columna correspondiente al tipo penal se asignó el número 1; para los procesos en los que se haya consolidado un acceso carnal y 2 para aquellos casos en los que la acusación se haya efectuado por un acto sexual abusivo. 


\section{VALIDEZ DE LA TÉCNICA ANÁLISIS DE CONTENIDO BASADO EN \\ CRITERIOS 36}

\section{Procedimiento}

El procedimiento de la investigación se dividió en las siguientes etapas

Etapa 1. Revisión de aquellos procesos penales adelantados por delitos sexuales referidos mediante denuncia formal o de oficio en el circuito de Fusagasugá, en el periodo comprendido entre el año 2009 y el año 2012, de los cuales, ya existía resolución judicial (V2) y donde las víctimas corresponden niñas entre 5 a 11 años.

Etapa 2. Recuperación de las entrevistas practicadas a niñas víctimas.

Etapa 3. Elaboración de la operacionalización de los 19 criterios con base en los referentes teóricos.

Etapa 4. Validación de la operacionalización de los 19 criterios por parte de jueces expertos.

Etapa 5. Aplicación de la técnica CBCA sobre las entrevistas recolectadas en la etapa 2. En ella se diligenció la Matriz No. 1 por cada uno de los evaluadores.

Etapa 6. Realización del análisis sobre las entrevistas mediante la aplicación de la técnica CBCA. Una vez se ha obtenido el puntaje total, se logró el puntaje definitivo para la variable 1 sobre la cual, se llevó a cabo el registro de los datos en la matriz de registro de resultados.

Etapa 7. Análisis estadístico, especificado en el cuerpo del presente documento.

Etapa 8. Interpretación de resultados a la luz de los instrumentos trabajados. 


\section{Resultados}

A continuación se presentan los resultados obtenidos de la aplicación de la técnica CBCA a entrevistas de niñas referidas mediante denuncia formal o de oficio, como víctimas de delitos sexuales ante la Unidad Seccional de Fiscalías del municipio de Fusagasugá, cuyo proceso ya cuenta con una sentencia judicial condenatoria. Aunque inicialmente se estimó una muestra de 20 casos, por factores ajenos al control de la muestra solo fue posible analizar la información proveniente de ocho casos que cumplen con los parámetros establecidos para la investigación.

Los resultados obtenidos se organizaron presentando en primer lugar la evaluación de validez de contenido de las definiciones operacionales para la calificación de los 19 criterios de la técnica CBCA (tabla 3 y 4, apéndice A). Posteriormente, se presenta el nivel de concordancia entre las puntuaciones de los jueces evaluadores en cada uno de los ocho casos analizados; se evaluó sí la implementación de estrategias diferentes de agregación de puntajes cuando se tienen varios evaluadores generan discrepancias en los resultados obtenidos (tabla 5). Finalmente, se expone la evaluación estadística de las dos estrategias de calificación (tabla 6) y se contrastan los puntajes en el CBCA con los referentes conceptuales a fin de obtener evidencia sobre la validez de la técnica (figura 1 y 2).

En este sentido, en primer lugar, con el objetivo de facilitar la comprensión de los referentes teóricos a la luz de la evidencia empírica, se estableció la validez de contenido de las operacionalizaciones realizadas a los 19 criterios del CBCA, por medio, del índice de concordancia, al tener como dimensiones de calificación la precisión, claridad y suficiencia de los mismos. Para esto, primero se realizaron las definiciones 
operacionales con base en los aspectos conceptuales expuestos en el marco teórico; posteriormente las definiciones fueron remitidas a cuatro expertos: Elizabeth León: Psicóloga jurídica y forense, doctora en ciencias de la salud y docente de la Universidad Nacional de la Plata (Chile), Wilmar Eduardo Rodríguez: Psicólogo jurídico y forense, profesional especializado del ICBF (Instituto Colombiano de Bienestar Familiar, Fusagasugá), José Luis Posada: Psicólogo, magíster en investigación en psicología, docente de psicometría (Fundación Universitaria Los Libertadores, Bogotá) y Alejando Jiménez: Psicólogo, magister en seguridad y defensa nacional, docente de psicología jurídica (Fundación Universitaria Los Libertadores, Bogotá).

Cada uno de los jueces expertos evaluó de forma independiente las definiciones operacionales de los 19 criterios del CBCA; con base en sus evaluaciones a los aspectos o dimensiones de precisión, claridad y suficiencia se obtuvo un índice de concordancia para cada una de ellas (tabla 3) y luego el índice global de validez de contenido (tabla 4). Estos procedimientos se realizaron con el coeficiente V de Aiken. Se encontró que para los 19 criterios del CBCA el índice global es de 0.83; considerando que Cicherti (1994 citado por Merino y Livia, 2009) establece como criterio liberal 0.50 como mínimo nivel de validez. De otro lado, Charter (2003, citado por Merino y Livia, 2009) siendo más conservador indica como mínimo nivel de validez 0.70 .

En este sentido, al obtener un índice de 0.83 se está por encima de ambos criterios de validez. Por tanto, tal como lo indica la tabla 4 el índice V de Aiken para la dimensión de precisión obtuvo un mínimo de 0.63 y un máximo de 0.88 , obteniendo media de 0.81; para la dimensión de claridad, las puntuaciones oscilaron entre 0.81 y 1 , 
con lo cual, obtuvo media 0.87 y por último, la dimensión de suficiencia cuenta con una media de 0.80 , siendo su puntuación mínima 0.69 y la máxima puntuación 0.88 .

Tabla 3

Validez de contenido de las definiciones operacionales de los 19 criterios del CBCA con base en la $V$ de Aiken.

\begin{tabular}{ccccccccccccccccc}
\hline \multicolumn{1}{c}{ Precisión } & \multicolumn{1}{c}{ Claridad } & \multicolumn{1}{c}{ Suficiencia } & \multicolumn{3}{c}{ Estimación V de Aiken } \\
No. & $\mathbf{J}$ & $\mathbf{J}$ & $\mathbf{J}$ & $\mathbf{J}$ & $\mathbf{2}$ & $\mathbf{J}$ & $\mathbf{J}$ & $\mathbf{J}$ & $\mathbf{J}$ & $\mathbf{J}$ & $\mathbf{J}$ & $\mathbf{J 4}$ & Precisió & Clarida & Suficienci & Global \\
\hline & $\mathbf{1}$ & $\mathbf{2}$ & $\mathbf{4}$ & $\mathbf{3}$ & $\mathbf{2}$ & $\mathbf{3}$ & $\mathbf{4}$ & $\mathbf{1}$ & $\mathbf{2}$ & $\mathbf{3}$ & & $\mathbf{n}$ & $\mathbf{d}$ & $\mathbf{a}$ & \\
\hline 1 & 4 & 4 & 5 & 4 & 4 & 5 & 5 & 4 & 4 & 4 & 5 & 4 & 0.81 & 0.88 & 0.81 & 0.83 \\
2 & 5 & 4 & 5 & 4 & 4 & 5 & 5 & 5 & 4 & 4 & 5 & 5 & 0.88 & 0.94 & 0.88 & 0.90 \\
3 & 4 & 4 & 5 & 5 & 4 & 5 & 5 & 5 & 4 & 4 & 5 & 5 & 0.88 & 0.94 & 0.88 & 0.90 \\
4 & 4 & 4 & 5 & 5 & 3 & 5 & 5 & 4 & 3 & 3 & 5 & 4 & 0.88 & 0.81 & 0.69 & 0.79 \\
5 & 4 & 4 & 5 & 5 & 3 & 5 & 5 & 4 & 4 & 3 & 5 & 4 & 0.88 & 0.81 & 0.75 & 0.81 \\
6 & 5 & 4 & 5 & 4 & 5 & 5 & 5 & 4 & 4 & 4 & 5 & 4 & 0.88 & 0.94 & 0.81 & 0.88 \\
7 & 3 & 4 & 5 & 4 & 4 & 5 & 4 & 4 & 3 & 4 & 5 & 4 & 0.75 & 0.81 & 0.75 & 0.77 \\
8 & 3 & 4 & 5 & 4 & 4 & 5 & 5 & 4 & 4 & 3 & 5 & 4 & 0.75 & 0.88 & 0.75 & 0.79 \\
9 & 3 & 4 & 5 & 5 & 3 & 5 & 5 & 4 & 4 & 4 & 5 & 4 & 0.81 & 0.81 & 0.81 & 0.81 \\
10 & 5 & 4 & 5 & 4 & 5 & 5 & 5 & 4 & 5 & 4 & 5 & 4 & 0.88 & 0.94 & 0.88 & 0.90 \\
11 & 4 & 4 & 4 & 5 & 4 & 5 & 4 & 4 & 4 & 4 & 4 & 4 & 0.81 & 0.81 & 0.75 & 0.79 \\
12 & 4 & 4 & 5 & 5 & 5 & 5 & 5 & 5 & 5 & 3 & 5 & 5 & 0.88 & 1.00 & 0.88 & 0.92 \\
13 & 3 & 4 & 5 & 4 & 3 & 5 & 5 & 4 & 3 & 4 & 5 & 4 & 0.75 & 0.81 & 0.75 & 0.77 \\
14 & 4 & 4 & 5 & 4 & 3 & 5 & 5 & 4 & 3 & 3 & 5 & 4 & 0.81 & 0.81 & 0.69 & 0.77 \\
15 & 2 & 4 & 5 & 3 & 3 & 5 & 5 & 4 & 3 & 4 & 5 & 4 & 0.63 & 0.81 & 0.75 & 0.73 \\
16 & 4 & 4 & 5 & 3 & 4 & 5 & 5 & 4 & 4 & 4 & 5 & 4 & 0.75 & 0.88 & 0.81 & 0.81 \\
17 & 4 & 4 & 5 & 4 & 4 & 5 & 5 & 4 & 4 & 4 & 5 & 4 & 0.81 & 0.88 & 0.81 & 0.83 \\
18 & 3 & 4 & 5 & 4 & 4 & 5 & 5 & 4 & 4 & 4 & 5 & 4 & 0.75 & 0.88 & 0.81 & 0.81 \\
19 & 5 & 4 & 5 & 4 & 5 & 5 & 5 & 4 & 5 & 4 & 5 & 4 & 0.88 & 0.94 & 0.88 & 0.90 \\
\hline
\end{tabular}

Paralelo a ello, al realizar una observación específica de cada una de las dimensiones, se evidencia que el criterio 15 admisión de falta de memoria con respecto a la dimensión de precisión puntúa por debajo de 0.70 , siendo su índice de 0.63 y los criterios 4 y 14 engranaje tiempo y espacio, así como, correcciones espontáneas respectivamente, puntúan 0.69 en la dimensión de suficiencia. No obstante, dicha puntuación se encuentra próxima al índice de validez de 0.70, y superior al límite establecido por Cicherti. Por consiguiente, se demuestra que existe consistencia en las 


\section{VALIDEZ DE LA TÉCNICA ANÁLISIS DE CONTENIDO BASADO EN \\ CRITERIOS 40}

operacionalizaciones que se realizaron de los 19 criterios del CBCA, lo cual, facilita la comprensión de los mismos y por ende, faculta su adecuada ponderación al momento de ser aplicada a las narrativas de presuntas víctimas de abuso sexual infantil.

Tabla 4

Estadísticos descriptivos dimensiones de la validez de contenido con $V$ de Aiken de las definiciones de los criterios del CBCA por cuatro jueces expertos.

\begin{tabular}{lccccc}
\hline & $\mathrm{N}$ & Mínimo & Máximo & $\mathrm{M}$ & D.E. \\
\hline Precisión & 19 & .63 & .88 & .81 & .07 \\
Claridad & 19 & .81 & 1.00 & .87 & .06 \\
Suficiencia & 19 & .69 & .88 & .80 & .06 \\
V de Aiken & 19 & .73 & .92 & .83 & .06 \\
\hline
\end{tabular}

El segundo aspecto analizado fue la consistencia en las evaluaciones realizadas por tres evaluadores o jueces (diferentes a los jueces expertos de la validez de contenido). Para este análisis se revisó la concordancia en las calificaciones de los tres jueces en cada uno de los 19 criterios del CBCA de forma independiente para cada uno de los ocho casos de la muestra. Para establecer el nivel de acuerdo, se tomó como parámetro la unanimidad de los tres jueces en la presencia o ausencia del criterio en cada una de las entrevistas; en la tabla 5 se presenta a manera de ejemplo el proceso realizado en cada uno de los ocho casos; los otros siete casos se encuentran en los anexos (Apéndice B).

En la tabla 5 se observa que para cada uno de los 19 criterios del CBCA, cada uno de los tres jueces indicó la presencia 1 o ausencia 0 del indicador en la entrevista realizada al participante 1 (S1). Posteriormente, se identificó el número de acuerdos presentados por los tres jueces en los 19 criterios. En este caso, se observa que los jueces 


\section{VALIDEZ DE LA TÉCNICA ANÁLISIS DE CONTENIDO BASADO EN \\ CRITERIOS 41}

concordaron en la calificación otorgada a 13 de los 19 criterios (ocho de presencia y cinco de ausencia), es decir, presentan un $68 \%$ de concordancia en la calificación de los criterios; los resultados para este análisis para los ocho casos se pueden observar en la tabla 6.

Tabla 5

Calificaciones de la entrevista realizada al participante 1 por parte de los tres evaluadores con base en la técnica $C B C A$, su concordancia unánime en cada criterio (A), la puntuación por mayoría $(S)$ y la puntuación promedio $(P)$.

\begin{tabular}{lcccccc}
\hline CBCA & S1-J1 & S1-J2 & S1-J3 & A1 & S1 & P1 \\
\hline CBCA1 & 1 & 1 & 1 & 1 & 1 & 1,00 \\
CBCA2 & 1 & 0 & 1 & 0 & 1 & 0,67 \\
CBCA3 & 1 & 0 & 1 & 0 & 1 & 0,67 \\
CBCA4 & 1 & 1 & 1 & 1 & 1 & 1,00 \\
CBCA5 & 1 & 1 & 1 & 1 & 1 & 1,00 \\
CBCA6 & 1 & 1 & 1 & 1 & 1 & 1,00 \\
CBCA7 & 1 & 0 & 0 & 0 & 0 & 0,33 \\
CBCA8 & 0 & 0 & 0 & 1 & 0 & 0,00 \\
CBCA9 & 1 & 1 & 1 & 1 & 1 & 1,00 \\
CBCA10 & 0 & 0 & 0 & 1 & 0 & 0,00 \\
CBCA11 & 1 & 0 & 1 & 0 & 1 & 0,67 \\
CBCA12 & 1 & 0 & 1 & 0 & 1 & 0,67 \\
CBCA13 & 1 & 1 & 1 & 1 & 1 & 1,00 \\
CBCA14 & 0 & 0 & 0 & 1 & 0 & 0,00 \\
CBCA15 & 1 & 0 & 1 & 0 & 1 & 0,67 \\
CBCA16 & 0 & 0 & 0 & 1 & 0 & 0,00 \\
CBCA17 & 1 & 1 & 1 & 1 & 1 & 1,00 \\
CBCA18 & 0 & 0 & 0 & 1 & 0 & 0,00 \\
CBCA19 & 1 & 1 & 1 & 1 & 1 & 1,00 \\
\hline
\end{tabular}

Un segundo procedimiento ilustrado en la tabla 5 consiste en la obtención de una calificación agregada o conjunta de los tres jueces en cada uno de los criterios del 


\section{VALIDEZ DE LA TÉCNICA ANÁLISIS DE CONTENIDO BASADO EN \\ CRITERIOS 42}

CBCA; esta calificación se obtuvo con base en dos estrategias que posteriormente se correlacionaron a fin de establecer concordancia entre los jueces. La primera calificación se realizó con base en la mayoría y la segunda con base en el promedio; así pues, para primera estrategia se tomó como presencia o ausencia del criterio cuando los tres jueces o dos de ellos así lo indicaban; en la segunda estrategia se promedió la calificación de los tres jueces, de tal manera que los puntajes posibles serían 1 cuando los tres jueces indicaban la presencia del criterio, 0,67 cuando dos así lo establecían, 0,33 cuando sólo uno indicaba la presencia y 0 cuando los tres jueces reportaban la ausencia del indicador. El primer participante obtuvo 13 puntos con la primera estrategia y 11,67 con la segunda y una correlación de 0,93 entre las dos. Los resultados de todos los participantes con este procedimiento se presenta en la tabla 6.

De otro lado, tal como lo indica la tabla 6 y de acuerdo a lo expuesto por GodoyCervera e Higueras (2005) con respecto al puntaje mínimo para establecer la credibilidad del testimonio, se puede evidenciar que los testimonios evaluados presentan puntajes superiores a 6 indicando ser testimonios creíbles. Lo cual, asevera que el referente empírico logrado en la presente investigación responde a los referentes teóricos que sustentan la utilización de la técnica del CBCA. 


\section{VALIDEZ DE LA TÉCNICA ANÁLISIS DE CONTENIDO BASADO EN \\ CRITERIOS 43}

Tabla 6

Puntuaciones en el CBCA de los ocho casos por cada experto, su nivel de acuerdo en las calificaciones de los 19 criterios y los puntajes agregados por dos estrategias (mayoría y promedio) junto con la correlación entre ellas.

\begin{tabular}{|c|c|c|c|c|c|c|c|c|}
\hline No. & J1 & J2 & J3 & $\begin{array}{l}\text { Acuerdos } \\
\text { (máx 19) }\end{array}$ & $\begin{array}{c}\text { Porcentaje } \\
\text { Acuerdos }\end{array}$ & $\begin{array}{l}\text { Puntaje } \\
\text { Mayoría }\end{array}$ & $\begin{array}{c}\text { Puntaje } \\
\text { Promedio }\end{array}$ & $\mathbf{R x y}$ \\
\hline S1 & 14 & 8 & 13 & 13 & 68 & 13 & 11.67 & 0.93 \\
\hline $\mathrm{S} 2$ & 9 & 6 & 8 & 15 & 79 & 9 & 7.67 & 0.97 \\
\hline S3 & 14 & 11 & 12 & 14 & 74 & 12 & 12.33 & 0.94 \\
\hline S4 & 11 & 10 & 12 & 17 & 89 & 11 & 11.00 & 0.98 \\
\hline S5 & 14 & 13 & 13 & 15 & 79 & 13 & 13.33 & 0.99 \\
\hline S6 & 12 & 8 & 11 & 13 & 68 & 11 & 10.33 & 0.93 \\
\hline S7 & 13 & 7 & 13 & 13 & 68 & 13 & 11.00 & 0.94 \\
\hline S8 & 15 & 12 & 14 & 14 & 74 & 14 & 13.67 & 0.92 \\
\hline \multicolumn{4}{|c|}{ promedios } & 14,25 & 75 & 12,00 & 11,38 & 0,95 \\
\hline
\end{tabular}

Con base en los procedimientos antes descritos, se encontró que el nivel de acuerdo entre los jueces para los 19 criterios del CBCA en los ocho casos analizados osciló entre $68 \%$ (casos 1, 6 y 7) y 89\% (caso 4); en promedio el porcentaje de acuerdos fue $75 \%$ (tabla 6); estos niveles de acuerdo resultan satisfactorios con base en los criterios de concordancia entre jueces para la $\mathrm{V}$ de Aiken previamente indicados. No obstante, estos resultados discrepan de los esperados (100\% de acuerdo), en la medida que la validez de contenido de las definiciones operacionales fue altamente satisfactoria. En este sentido, estos resultados indican que la técnica CBCA aún contiene un margen de subjetividad en la calificación de los criterios por parte de los evaluadores (figura 1). 


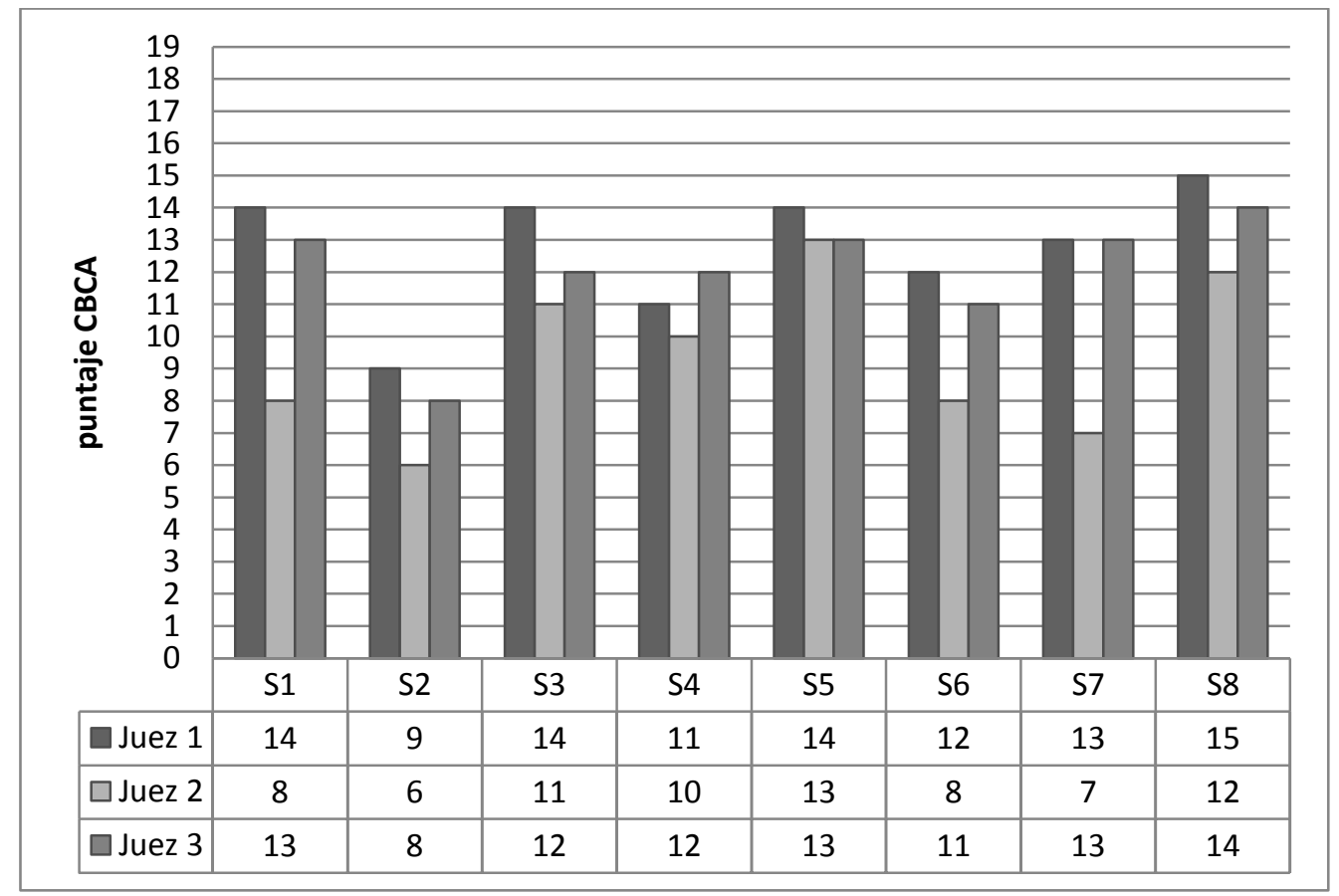

Figura 1. Puntuaciones totales de los jueces para el CBCA en cada uno de los 8 casos analizados.

Dada las implicaciones prácticas de lo anterior, se procedió a la estimación agregada o conjunta de los criterios del CBCA con base en dos estrategias diferentes, tal como ya se indicó previamente. En la tabla 6 se puede observar que solo en una ocasión las dos estrategias generan una puntuación idéntica (caso 4); sin embargo, se encontró que estas diferencias observadas no son estadísticamente significativas (tabla 7), por lo que se concluye que cuando se tienen varios evaluadores no importa la estrategia de calificación (mayoría o promedio), pues, las discrepancias observadas no representan un riesgo importante para la puntuación final de la técnica CBCA (figura 2). 
Tabla 7

Prueba de muestras emparejadas para puntuaciones del CBCA obtenidas por mayoría o promedio en los calificaciones de los 19 criterios.

\begin{tabular}{|c|c|c|c|c|c|c|c|c|}
\hline & \multicolumn{5}{|c|}{ Diferencias emparejadas } & \multirow[b]{3}{*}{$\mathrm{t}$} & \multirow[b]{3}{*}{$\mathrm{gl}$} & \multirow{3}{*}{$\begin{array}{c}\text { Sig. } \\
\text { (bilateral) } \\
\end{array}$} \\
\hline & \multirow[b]{2}{*}{ Media } & \multirow{2}{*}{$\begin{array}{c}\text { Desviación } \\
\text { estándar }\end{array}$} & \multirow{2}{*}{$\begin{array}{l}\text { Media de } \\
\text { error } \\
\text { estándar }\end{array}$} & \multicolumn{2}{|c|}{$\begin{array}{c}95 \% \text { de intervalo de } \\
\text { confianza de la diferencia }\end{array}$} & & & \\
\hline & & & & Inferior & Superior & & & \\
\hline $\begin{array}{l}\text { Mayoría - } \\
\text { Promedio }\end{array}$ & ,62500 & ,86093 & ,30438 &,- 09476 & 1,34476 & 2,053 & & ,079 \\
\hline
\end{tabular}

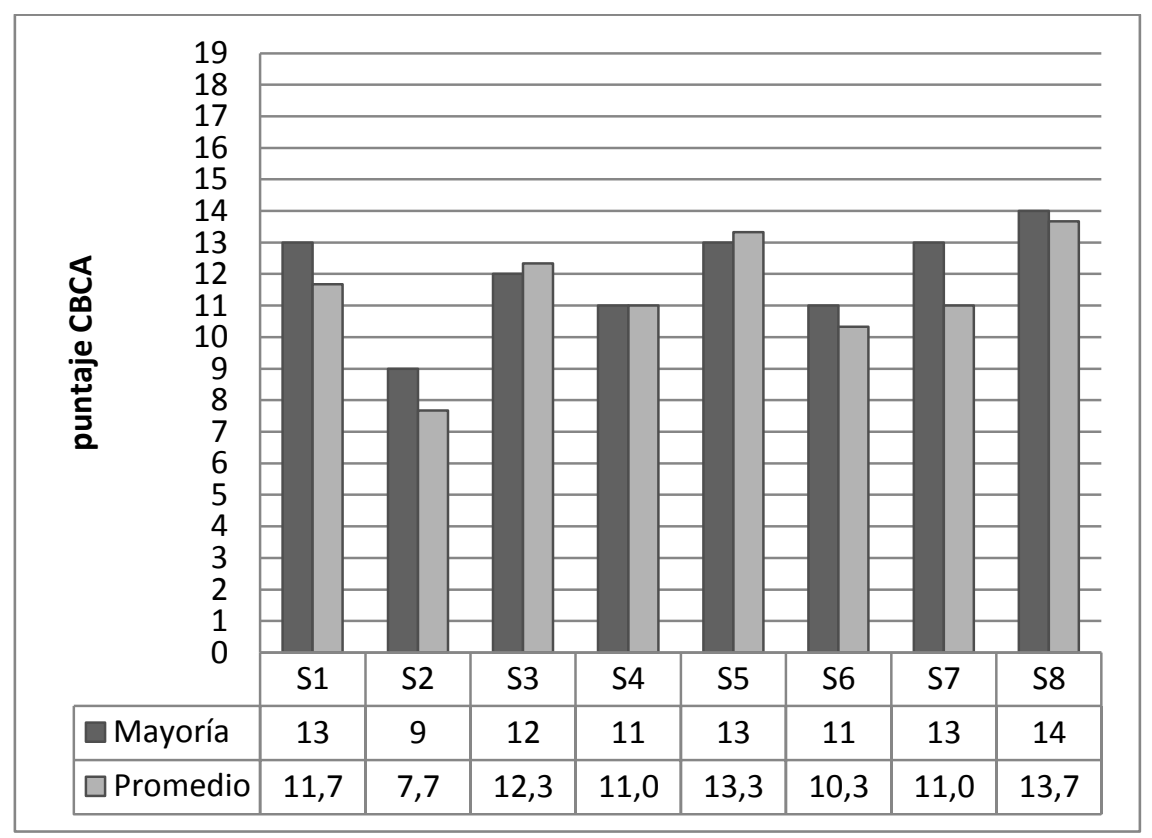

Figura 2. Puntuaciones totales del CBCA en cada uno de los 8 casos analizados con base en la estrategia mayoría y promedio. 


\section{VALIDEZ DE LA TÉCNICA ANÁLISIS DE CONTENIDO BASADO EN \\ CRITERIOS 46}

\section{Discusión}

La presente investigación tuvo como objetivo general estimar la confiabilidad y la validez de la Técnica Análisis de Contenido Basado en Criterios (CBCA) a partir del análisis del testimonio de niños, niñas y adolescentes víctimas de delitos sexuales cuyos agresores presentan sentencia condenatoria por el juez de conocimiento de primera instancia. Para el cumplimiento de este objetivo se procedió a localizar las entrevistas realizadas a las presuntas víctimas de delitos sexuales en el Circuito Penal de Fusagasugá; en esta búsqueda se encontraron ocho casos que presentaban sentencia condenatoria en primera instancia, por lo que la meta de contar con 20 testimonios no se pudo cumplir y la investigación se llevó a cabo con todas las que cumplían los criterios de inclusión, en tal sentido, el estudio se toma como censal. En el circuito existen otros casos sobre delitos sexuales contra menores de edad pero se encuentran en curso y en consecuencia no cumplían con los criterios de inclusión establecidos en esta investigación.

Para el cumplimiento del objetivo investigativo, antes de analizar los testimonios con la técnica CBCA fue necesario estimar la validez de las definiciones operacionales de los 19 criterios de esta. Para responder a este objetivo específico se inició con la definición operacional de los criterios y posteriormente, se acudió a la evaluación independiente de jueces expertos, quienes revisaron la precisión, claridad y suficiencia de cada criterio. Con base en tales evaluaciones se realizó la estimación por medio del índice V de Aiken para validez de contenido (Aiken, 1996; Carretero-Dios y Pérez, 2007; Merino y Livia, 2009). 


\section{VALIDEZ DE LA TÉCNICA ANÁLISIS DE CONTENIDO BASADO EN \\ CRITERIOS 47}

Los resultados de la estimación de la validez de contenido indican que las definiciones operacionales de los criterios del CBCA son precisas entre 0,63 y 0,88 , son claras entre 0,81 y 1,00 y son suficientes entre 0,69 y 0,88 , lo cual, lleva a que la validez de contenido de los criterios oscilen entre 0,73 y 0,92 cuando se combinan las tres dimensiones examinadas. En promedio los criterios presentan una validez de contenido de 0,83 ; este resultado se puede catalogar como un nivel muy alto de acuerdo con los parámetros interpretativos reportados por Merino y Livia (2009), en los cuales el valor de referencia mínimo para la $\mathrm{V}$ de Aiken es 0,70 siguiendo una postura conservadora que es más exigente que la liberal $(0,50)$.

En este análisis de validez de contenido se encontraron tres criterios que presentaron valores inferiores a 0,70 ; concretamente, el criterio 15 presentó una $\mathrm{V}$ de Aiken de 0,63 en precisión de la operacionalización y los criterios 4 y 14 presentaron un resultado de 0,69 en la suficiencia de la definición. No obstante, cuando se combinaron las tres dimensiones evaluadas, los resultados para estos tres criterios fueron 0,$79 ; 0,77$; y 0,73 respectivamente, es decir, que la validez de contenido de las operacionalizaciones de estos criterios cumplen con el estándar reportado en la literatura. Los resultados obtenidos en la validez de contenido de las definiciones operacionales respaldan el uso de la técnica CBCA en el contexto colombiano, pues, a la luz de expertos en medición psicológica y en psicología jurídica y forense las definiciones tienen un nivel muy alto, por lo que se espera que los usuarios de la técnica se basen en las definiciones aquí aportadas.

Un segundo objetivo específico en esta investigación fue la estimación de la confiabilidad inter-jueces en la evaluación del testimonio de niños, niñas y adolescentes 
víctimas de delitos sexuales en el municipio de Fusagasugá. Para dar respuesta a este objetivo, se realizó la aplicación de la técnica CBCA a las entrevistas transcritas de ocho víctimas de estos delitos.

La evaluación de cada testimonio fue realizada de manera independiente por tres jueces evaluadores, las dos autoras de esta investigación y una tercera evaluadora independiente que no participó en la elaboración de las definiciones operacionales, ni conocía el sentido de la sentencia judicial de los casos analizados, es decir, realizó una evaluación ciega de los testimonios con base únicamente de las definiciones elaboradas y suministradas para cada criterio. Su formación académica especializada en psicología jurídica, así como, funcionaria del Centro de Atención Integral a Víctimas de Abuso Sexual CAIVAS del Instituto Colombiano de Bienestar Familiar ICBF Fusagasugá; adicionalmente, una de las autoras cuenta con un master internacional en psicología forense y es funcionaria del CTI de la Fiscalía General de la Nación en la Unidad de Delitos Sexuales; la otra evaluadora es psicóloga, candidata a magister en psicología jurídica y cuenta con experiencia docente en áreas de psicología diferencial y procesos psicológicos básicos. Las instrucciones para cada evaluador fue determinar la presencia o ausencia de cada criterio del CBCA con base en las definiciones suministradas.

Una vez aplicada la técnica CBCA de manera independiente por los tres evaluadores a cada uno de los ocho testimonios en casos de delitos sexuales a niños, niñas y adolescentes en el municipio de Fusagasugá, se procedió a estimar la confiabilidad inter-jueces en la calificación de los criterios de la técnica CBCA. Los resultados obtenidos muestran que hubo entre 13 y 17 acuerdos en los 19 criterios entre los tres evaluadores, lo cual, en términos porcentuales equivale a acuerdos entre $68 \%$ y 


\section{VALIDEZ DE LA TÉCNICA ANÁLISIS DE CONTENIDO BASADO EN \\ CRITERIOS 49}

$89 \%$; en promedio para los ocho casos los jueces tuvieron un nivel de acuerdo en la calificación de los 19 criterios de 75\%; lo anterior, de acuerdo con Aiken (1996) resulta ser satisfactorio si se aplica el parámetro de 0,70 para acuerdos entre jueces implicado en la técnica $\mathrm{V}$ de Aiken. No obstante, este resultado también implica que hay un $25 \%$ de inconsistencia en la aplicación de los criterios, aspecto crítico que se le ha hecho a la técnica CBCA de tener un componente subjetivo en determinación de credibilidad (Tapias et al., 2004).

Teniendo en cuenta el resultado anterior, la descripción de la credibilidad del testimonio en casos de delitos sexuales a niños, niñas y adolescentes en el municipio de Fusagasugá que constituye el tercer objetivo específico de esta investigación, permitió identificar qué tanto afectaba estas variaciones inter-evaluadores las puntuaciones de la técnica CBCA, en tanto, se procedió a obtener la puntuación en cada criterio con base en dos estrategias distintas; la primera, se realizó por mayoría o unanimidad y la segunda con base en el promedio de las calificaciones dadas por cada evaluador. Siguiendo estas estrategias no sólo se buscó controlar el efecto de subjetividad en las calificaciones al tener puntuaciones agregadas o conjuntas, también, identificar si hay discrepancias entre las dos estrategias de calificación descritas.

Los resultados indican que las calificaciones de los criterios siguiendo las dos estrategias presentan correlación de 0,95 en promedio para los ocho casos, es decir, que existe alta consistencia a nivel de los 19 criterios con base en las dos estrategias de calificación. Sin embargo, cuando se revisan las puntuaciones totales de los ocho casos con base en las dos estrategias se observa que únicamente en uno de los ocho casos las dos estrategias generan un resultado idéntico, mientras que, en los otros siete casos hay 


\section{VALIDEZ DE LA TÉCNICA ANÁLISIS DE CONTENIDO BASADO EN \\ CRITERIOS 50}

diferencias que oscilan entre 0,33 y 2 puntos; estas diferencias se sometieron a prueba con base en una comparación de medias de muestras relacionadas (prueba t de student) y se encontró que las diferencias entre los resultados totales de las dos estrategias no son estadísticamente significativas. Este resultado permite concluir que cuando se tienen varios evaluadores se puede usar cualquiera de las dos estrategias aquí implementadas, puesto que, las diferencias en los resultados no resultan significativas, por tanto, para efectos prácticos se puede tomar la puntuación por mayoría y si se desea mayor precisión se puede realizar la calificación por promedio.

Teniendo controlado el efecto de subjetividad con base en las calificaciones conjuntas se pudo realizar una descripción de la credibilidad del testimonio en casos de delitos sexuales a niños, niñas y adolescentes en el municipio de Fusagasugá lo que constituye el cuarto objetivo específico de esta investigación. Al considerar que los testimonios analizados con la técnica CBCA en esta investigación proceden de víctimas de delitos sexuales, cuyos agresores cuentan con sentencia condenatoria en primera instancia por el juez de conocimiento del Circuito de Fusagasugá, y siendo esto el criterio independiente de validez, se presume que los testimonios son creíbles y en consecuencia la técnica deberá presentar puntajes superiores a 6 puntos para ser concurrentes con la sentencia (Godoy-Cervera e Higueras, 2005), es decir, que apunten a que el testimonio tiene credibilidad.

Los resultados obtenidos así lo muestran, puesto que, el caso 2 que fue el que presentó menor puntaje recibió 9 puntos en la calificación conjunta por mayoría y 7,67 en la calificación promedio de los tres evaluadores. En este caso, uno de los jueces encontró la presencia de seis criterios del CBCA, mientras que, los otros dos 


\section{VALIDEZ DE LA TÉCNICA ANÁLISIS DE CONTENIDO BASADO EN \\ CRITERIOS 51}

evaluadores encontraron ocho y nueve criterios respectivamente, es decir, aún en el caso donde hubo menores indicadores de la credibilidad según uno de los evaluadores, esta supera el límite inferior propuesto por Godoy-Cervera et al. (2005) para considerar el testimonio como creíble. En consecuencia, para esta muestra de Fusagasugá, la técnica CBCA es una herramienta válida para detectar la credibilidad del testimonio aplicando los mismos estándares internacionales de acuerdo con lo reportado por Vrij, (2000) y Godoy-Cervera e Higueras (2005), entre otros, en especial si se aplica la calificación conjunta por mayoría, pues, en los ocho casos se encontró en promedio la presencia de 12 criterios del CBCA, oscilando entre 9 (caso 2) y 14 (caso 8) teniendo en cuenta la puntuación conjunta de tres evaluadores independientes.

Los resultados aquí reportados muestran consistencia inter-jueces tanto en las definiciones operacionales como en la aplicación de tales definiciones en los ocho casos analizados, así mismo, las dos estrategias de calificación resultaron consistentes entre sí y resultan coincidentes con el sentido de la sentencia. No obstante, se requiere continuar trabajando en el incremento de la consistencia en la calificación de los criterios de la técnica $\mathrm{CBCA}$, pues, aún hay fuentes de variación que no corresponden a la falta de definiciones operacionales, sino posiblemente a la formación y experiencia del evaluador. Este aspecto se constituye en un área para continuar la investigación sobre el CBCA en población colombiana. 


\section{VALIDEZ DE LA TÉCNICA ANÁLISIS DE CONTENIDO BASADO EN \\ CRITERIOS 52}

\section{Conclusiones y recomendaciones}

Bajo la perspectiva de esta investigación, aspectos como la subjetividad en la calificación, la operacionalización de los criterios que estructuran la técnica y la validación del CBCA a la luz de un criterio externo como la sentencia judicial, fueron subsanados a partir de las recomendaciones derivadas de su estudio predecesor desarrollado por Tapias et al (2004). Sin embargo, son tres los elementos fundamentales que se deberán abordar en nuevas propuestas que propendan por la optimización de la técnica en el contexto forense. Así, el tamaño de la muestra, la utilización de narraciones obtenidas a partir de protocolos de entrevistas forenses y el contar con un criterio de validación externo absolutorio, pues, son factores que pueden representan una fuente de variación a nivel de la confiabilidad y validez.

En primera instancia, el número de participantes con que se contó para este estudio fue muy reducido en razón a que, una vez surtidas las etapas propias del proceso de indagación, no se llegó al momento más significativo del juicio oral. De esta manera, aun cuando se contaba con la unidad de medida objeto de análisis, el criterio de validación externo no fue producido por la instancia judicial competente, limitando de esta forma la muestra a 8 casos.

Por otra parte, las unidades objeto de análisis fueron obtenidas por medio de la técnica de entrevista semi-estructurada, no contando a la fecha con datos precisos respecto a la validez y confiabilidad de aquellas declaraciones aportadas a través de la aplicación de protocolos de entrevista forense como el NICHD (National Institute of Child Health and Human Development), Michigan, StepWise, entre otros. En consecuencia, debido a que en la actualidad gran cantidad de las declaraciones rendidas 


\section{VALIDEZ DE LA TÉCNICA ANÁLISIS DE CONTENIDO BASADO EN \\ CRITERIOS 53}

por menores presuntas víctimas de delitos sexuales son recabadas mediante el uso de protocolos de entrevista forense, resulta preciso indagar si las propiedades psicométricas de la técnica presentan la misma tendencia evidenciada en este estudio, cuando la unidad de medida se obtiene a partir del uso de dichos protocolos de entrevista forense.

Finalmente, para futuras investigaciones se recomienda contar con el criterio de validación externo correspondiente a sentencias absolutorias, de manera tal que sea posible derivar análisis estadísticos integrales, que supongan la aceptación de la técnica como herramienta válida para la estimación de la credibilidad el testimonio infantil en casos de delitos sexuales en el contexto forense. 


\section{VALIDEZ DE LA TÉCNICA ANÁLISIS DE CONTENIDO BASADO EN \\ CRITERIOS 54}

\section{Referencias}

Akehurst, L., Manton, S. y Quandte, S. (2011). Careful calculation or a leap of faith? A field study of the translation of CBCA ratings to final credibility judgements. Applied Cognitive Psychology, 25, 236-243.

Aiken, L. R. (1996). Tests psicológicos y evaluación. México: Prentice Hall.

Arce, R y Fariña, F (2005). Peritación psicológica de la credibilidad del testimonio, la huella psíquica y la simulación: el sistema de evaluación global (SEG). Papeles del Psicólogo, 26, 59-77

Asamblea Nacional Constituyente (1991). Constitución Política de Colombia de 1991.

Recuperado de de http://www.alcaldiabogota.gov.co/sisjur/normas/Norma1.jsp?i=4125

Barraza, C., Buenahora, N., Caicedo, L., Benjumea, A. y Poveda, N. (2010). Estudio de la jurisprudencia colombiana en casos de delitos sexuales cometidos contra mujeres y niñas. Corporación Humanas. Centro Regional de Derechos Humanos y Justicia de Género. Recuperado de http://www.humanas.org.co/archivos/estudio_de_la_jurisprudencia.pdf

Bedoya, L. y Londoño, J. (2008). La prueba en el proceso penal colombiano. Bogotá: Fiscalía General de la Nación. ISBN 978-958-8374-10-9. Recuperado de http://www.fgiscalia.gov.co/colombia/wpcontent/uploads/2012/01/LaPruebaenelProcesoPenalColombiano.pdf

Blandon-Gitlin, I., Pezdek, K., Lindsay, D.S. y Hagen, L. (2008). Criteria Based Content Analysis of the true and suggested accounts of events. Applied Cognitive Psychology, 23: 901-917. Recuperado de www.interscience.wiley.com 


\section{VALIDEZ DE LA TÉCNICA ANÁLISIS DE CONTENIDO BASADO EN \\ CRITERIOS 55}

Cantón, J. y Cortés, M. (2007) Guía para la evaluación del abuso sexual infantil (2a . Ed.). (pp.123-146). Madrid: Pirámide.

Carretero-Dios y Pérez (2007) Standards for the development and review of instrumental studies: Considerations about test selection in psychological research. International Journal of Clinical and HealthPsychology. 7(3), 863-882.

Congreso de la República de Colombia (2004). Ley 599 de 2000. Recuperado de http://www.alcaldiabogota.gov.co/sisjur/normas/Norma1.jsp?i=6388

Congreso de la República de Colombia (2004). Ley 906 de 2004. Recuperado de http://www.secretariasenado.gov.co/senado/basedoc/ley/2004/ley_09060_204a.h tml

Congreso de la República de Colombia (2006). Ley 1098 de 2006. Recuperado de http://www.alcaldiabogota.gov.co/sisjur/normas/Norma1.jsp?i=22106

Consejo Nacional de Policía Judicial (2005). Manual único de policía judicial. Recuperado de http://www.dmsjuridica.com/Docs/Manuales/manualPolicia.pdf.

Corte Constitucional de Colombia. Sala Plena. (2005). Sentencia C-674 del 30 de junio de 2005. Recuperado de http://www.corteconstitucional.gov.co/relatoria/2005/c674-05.htm

Corte Constitucional de Colombia. Sala Plena. (2005). Sentencia T-453 del 2 de mayo de 2005. Recuperado de http://www.corteconstitucional.gov.co/relatoria/2005/t453-05.htm

Corte Suprema de Justicia. Sala de casación penal. Sentencia 34434 del 09 de diciembre de 2010. Magistrado ponente Sigfredo Espinosa Pérez 


\section{VALIDEZ DE LA TÉCNICA ANÁLISIS DE CONTENIDO BASADO EN \\ CRITERIOS 56}

Corte Suprema de Justicia. Sala de Casación Penal. (2006). Sentencia del 13 de julio de 2006.

Recuperado

de http://webcache.googleusercontent.com/search?q=cache:inGA_VFTHlwJ:190.24 .134.69/sentencias/penal/2006/Dr.\%25C3\%2581lvaro\%2520Orlando\%2520P\%2 5C3\%25A9rez\%2520Pinz\%25C3\%25B3n/Julio/23027(13-07-

06).doc $+\& \mathrm{~cd}=1 \& \mathrm{hl}=\mathrm{es} \& \mathrm{ct}=\mathrm{clnk} \& \mathrm{gl}=\mathrm{co}$

Corte Suprema de Justicia. Sala de Casación Penal. (2007). Sentencia del 23 de mayo de 2007. Magistrado ponenteJorge Luis Quintero Milanés. Recuperado de http://webcache.googleusercontent.com/search?q=cache:_fAA9os5PQ8J:190.24. 134.69/sentencias/penal/2007/Dr.Jorge\%2520Luis\%2520Quintero\%2520Milane s/Mayo/22203(23-05-07).doc $+\& \mathrm{~cd}=1 \& \mathrm{hl}=\mathrm{es} \& \mathrm{ct}=\mathrm{clnk} \& \mathrm{gl}=\mathrm{co}$

Corte Suprema de Justicia. Sala de Casación Penal. (2008). Sentencia del 5 de noviembre de 2008. Magistrado ponente Augusto J. Ibáñez Guzmán. Disponible en http://www.icbf.gov.co/cargues/avance/docs/csj_scp_30305(05-1108)_2008.htm

Corte Suprema de Justicia. Sala de Casación Penal. (2008). Sentencia del 17 de septiembre de 2008. Magistrado ponente Javier Zapata Ortiz. Disponible enhttp://webcache.googleusercontent.com/search?q=cache:3dhuLmp_pwJ:190.24.134.121/webcsj/Documentos/Penal/Genero/ACEESO\%2520CARNA L/21691(17-09-08).doc $+\& \mathrm{~cd}=1 \& \mathrm{hl}=\mathrm{es} \& \mathrm{ct}=\mathrm{clnk} \& \mathrm{gl}=\mathrm{co}$

Cronch, L., Viljoen, J. y Hansen, D. (2006). Forensic interviewing in child sexual abuse cases: Current techniques and future directions. Aggression and Violent Behavior. Recuperado de 


\section{VALIDEZ DE LA TÉCNICA ANÁLISIS DE CONTENIDO BASADO EN \\ CRITERIOS 57}

http://digitalcommons.unl.edu/cgi/viewcontent.cgi $?$ article=1005\&context=psych facpub

Escobar, A. y Fontecha, R. (2005). Diferencias en la validación del testimonio, a partir de las técnicas de entrevista cognitiva (E.C.) y el análisis de contenido basado en criterios (C.B.C.A), en niños de 10 años de edad, pertenecientes al colegio Miravalle, residentes en Bogotá D.C. Fundación Universitaria Los Libertadores. Bogotá.

Escobar-Córdoba, F (2008). La esquiva definición del derecho, a la luz de los códigos mesopotámicos. Recuperado de http://www.scielo.org.co/pdf/vniv/n117/n117a04.pdf

Espinosa, A. (2011). La Psicología del Testimonio. En G. Hernández (Ed.), Psicología Jurídica Iberoamericana. (pp. 197 - 230). Bogotá: Manual Moderno.

Fonseca, L. (2012). Dignificación del ser mujer, consolidación de derechos rol de la psicología jurídica. Recuperado de http://psicologiajuridica.org/archives/2956

Geiselman, R. y Fisher, R. (1994). La técnica de entrevista cognitiva para víctimas y testigos de crímenes. En Raskin, D.C. Métodos psicológicos en la investigación y pruebas criminales (pp 168-188)

Godert, H., Gamer, M., Rill, H. y Vossel, G. (2005). Statement validity assessment: Inter-rater reliability of criteria-based content analysis in the mock-crime paradigm. Legal and Criminological Psychology, 10, 225-245. 


\section{VALIDEZ DE LA TÉCNICA ANÁLISIS DE CONTENIDO BASADO EN \\ CRITERIOS 58}

Godoy-Cervera, V., e Higueras, L. (2005). El análisis de contenido basado en criterios (CBCA) en la evaluación de la credibilidad del testimonio. Recuperado de http://redalyc.uaemex.mx/pdf/778/77809204.pdf

Instituto Nacional de Medicina Legal y Ciencias Forenses. (2010). Guía para la realización de pericias psiquiátricas o psicológicas forenses en niños, niñas y adolescentes presuntas víctimas de delitos sexuales. Bogotá.

International criminal investigative training assistance program ICITAP. United States Department of Justice. (2008). Curso de Entrevista Forense a Niños y su Preparación para el Juicio. Bogota.

International criminal investigative training assistance program ICITAP. United States Department of Justice (2009). Curso Avanzado en Técnicas de Entrevista. Bogotá.

International criminal investigative training assistance program ICITAP. United States Department of Justice. (2011). Postcurso de Entrevista a Forense a Niños. Protocolo SATAC II. Bogotá.

Jiménez, C., y Martín, C. (2006).Valoración del testimonio en abuso sexual infantil (A.S.I.). Recuperado de http://scielo.isciii.es/pdf/cmf/n43-44/07.pdf

León, C. y Alegría, D. (2010). La entrevista entendida como prueba en la Ley 906 de 2004. Recuperado de http://repository.unimilitar.edu.co/bitstream/10654/3666/2/LeonPatinoCarmenEli sa2010.pdf 


\section{VALIDEZ DE LA TÉCNICA ANÁLISIS DE CONTENIDO BASADO EN \\ CRITERIOS 59}

Manzanero, A (2001). Procedimientos de evaluación de la credibilidad de las declaraciones de menores víctimas de agresiones sexuales. Psicopatología Clínica, Legal y Forense, 1(2), 51-71.

Manzanero, A. (2008). Psicología del testimonio. Una aplicación de los estudios sobre la memoria. Madrid: Psicología Pirámide.

Merino, C. y Livia, J. (2009). Intervalos de confianza asimétricos para el índice la validez de contenido: Un programa Visual Basic para la V de Aiken. Revista Anales de Psicología, 25 (1). Recuperado de http://www.um.es/analesps/v25/v25_1/19-25_1.pdf

Ministerio de protección social. (2006). Informe especial sobre la violencia contra la infancia en Colombia. Recuperado de http://www.catedradh.unesco.unam.mx/BibliotecaV2/Documentos/Trata/Informe s/informe_infancia.pdf

Mir, S. (2003). Introducción a las bases del derecho penal. Buenos Aires: Euros editores.

Montero y León (2007) A guide for naming research studies in Psychology. International Journal of Clinical and Health Psychology, 7 (3), 847-862.

Orts, E., González, J., Matallín, A., Roig, M. (2007). Derecho penal parte general. Valencia: Tirant lo Blanch

Pezdek, K., Morrow, A., Blandon-Gitlin, I., Goodman, S., Quas, J., Saywitz, K., Bidrose, S., Pipe, M., Rogers, M., y Brodie, L. (2004). Detecting deception in children: Event familiarity affects criterion-based content analysis. Recuperado de http://www.cgu.edu/include/Detecting\%20Deception\%20in\%20Children.pdf 


\section{VALIDEZ DE LA TÉCNICA ANÁLISIS DE CONTENIDO BASADO EN \\ CRITERIOS 60}

Plascencia, R. (sf) Los medios de prueba en materia penal. Recuperado de http://biblio.juridicas.unam.mx/revista/pdf/DerechoComparado/83/art/art9.pdf

Raskin, D. y Esplin, P. (1991). Statement Validity Assessment: interview procedures and content analysis of children's statements of sexual abuse. Behavioural Assessment, 13, 265-291.

Rodríguez, F., Bringas, C., Fariña, F., Arce, R. y Bernardo, A (2008) Psicología jurídica entorno judicial y delincuencia. Sociedad española de Psicología Jurídica y Forense. Recuperado de http://gip.uniovi.es/T5EJD.pdf

Steller, M., y Koehnken, G. (1994). La técnica de entrevista cognitiva para víctimas y testigos de crímenes. En D.C Raskin (Ed.), Métodos psicológicos en la investigación y pruebas criminales (pp 189-211).

Tapias, A. y Hernández, G. (2011). Psicología jurídica: una aproximación conceptual. En Hernández, G. (Editor), Psicología jurídica iberoamericana (pp. 1-22). Bogotá: Manual moderno.

Tapias, A., Aguirre, O., Moncada, A y Torres, A. (2004). Validación de la técnica “Análisis de Contenido Basado en Criterios" para evaluar credibilidad del testimonio en menores presuntas víctimas de delitos sexuales, que asisten a la unidad local de la atención al menor (ULAM) del Instituto Nacional de Medicina Legal y Ciencias Forenses en Bogotá. Disponible en www.psicologiajuridica.org

Vergel, J (2011). Descripción epidemiológica de los exámenes sexológicos forenses, Colombia, 2011: una aproximación a la violencia sexual en nuestro país.Recuperadode 
http://www.medicinalegal.gov.co/images/stories/root/FORENSIS/2011/5-F-11Sexologicos.pdf

Vrij, A. (2000). Detecting lies and deceit: The psychology of lying and its implications for professional practice. Chichester: John Wiley and Sons.

Vrij, A. (2005). Criteria Based - Content Analysis. A qualitative review of the first 37 studies. Psychology, Public Policy, and Law, 11 (1), 3-4.

Vrij, A., Akehurst, L., Soukara, S., y Bull, R. (2006). Let me inform you how to tell a convincing story: $\mathrm{CBCA}$ and reality monitoring scores as a function of age, coaching, and deception. Canadian Journal of Behavioral Science/Revue Canadienne des Sciences du Comportement, 36 (2), 113-126.

Vrij, A. y Mann, S. (2006). Criteria-Based Content Analysis: An empirical test of its underlying processes. Psychology, Crime and Law, 12 (4), 337-349. 
Apéndice A.

Evaluación de Validez de Contenido de las Definiciones Operacionales para la

Calificación de los 19 Criterios de la Técnica CBCA

\section{Revisión y validación de la operacionalización criterios CBCA Juicio de expertos}

Instrucciones:

1. Use el siguiente formato para expresar su apreciación y calificación sobre la operacionalización de cada uno de los 19 criterios del CBCA, en cuanto, su precisión, claridad y suficiencia para la comprensión de los mismos.

2. Por favor al momento de calificar la operacionalización de los criterios, tenga en cuenta que los siguientes criterios.

Precisión: hace referencia a la rigurosidad y exactitud de la definición conceptual proporcionada por los referentes teóricos.

Claridad: refiere la adecuada ilación y redacción de cada una de las enunciaciones que componen el instrumento, en relación a la población objetivo

Suficiencia: se relaciona con la capacidad gramatical para explicar las enunciaciones y favorecer su comprensión.

3. La calificación sobre precisión, claridad y suficiencia, se realizará con base en una escala Likert de 1-5, siendo:

- 1: Ausente

- 2: Insuficiente

- 3: Aceptable

- 4: Adecuado

- 5: Sobresaliente

4. En caso de tener observaciones y/o sugerencias sobre la operacionalización de los criterios, por favor escríbalas en el espacio de observaciones, el cual, se encuentra al final del documento.

Nuevamente, agradecemos su participación en la revisión y validación de la operacionalización de los 19 criterios CBCA.

Nombre completo:

Escolaridad:

Cargo: 


\section{Revisión y validación de la operacionalización criterios CBCA Juicio de expertos}

\begin{tabular}{|c|c|c|c|c|c|c|}
\hline Nro. & $\begin{array}{l}\text { Nombre del } \\
\text { criterio }\end{array}$ & Operacionalización & Descripción / Ejemplo & Precisión & Claridad & Suficiencia \\
\hline 1 & Estructura lógica & $\begin{array}{l}\text { Este criterio está presente } \\
\text { cuando los testimonios } \\
\text { muestran consistencia lógica } \\
\text { y/o homogeneidad contextual } \\
\text { durante todo el relato (Steller } \\
\text { y Koehnken, 1994; Vrij, } \\
\text { 2005). De esta forma, se tiene } \\
\text { como presente el criterio } \\
\text { cuando los detalles o } \\
\text { elementos de una declaración } \\
\text { describen de forma } \\
\text { independiente y } \\
\text { complementaria el mismo } \\
\text { curso del evento, es decir } \\
\text { hacen que la declaración } \\
\text { encaje (Trankell, 1972 citado } \\
\text { por Steller y Koehnken, } \\
\text { 1994). }\end{array}$ & $\begin{array}{l}\text { El análisis se hace sobre } \\
\text { el contenido total del } \\
\text { relato. }\end{array}$ & & & \\
\hline 2 & $\begin{array}{l}\text { Elaboración } \\
\text { inestructurada } \\
\text { (No Orden } \\
\text { Cronológico) }\end{array}$ & $\begin{array}{l}\text { Este criterio se encuentra en } \\
\text { una declaración cuando la } \\
\text { información no es entregada } \\
\text { en una secuencia cronológica } \\
\text { de tiempo (Vrij, 2005). Tal } \\
\text { como lo plantean Steller et al. } \\
\text { (1994), los elementos que } \\
\text { componen la declaración están } \\
\text { disgregados o completamente } \\
\text { desordenados, no rigiéndose } \\
\text { por una secuencia de sucesos } \\
\text { en orden cronológico; pero } \\
\text { formando un todo unificado } \\
\text { bajo un análisis global. Así, } \\
\text { este criterio se puntúa presente } \\
\text { cuando se presentan saltos en } \\
\text { la narración y no existe una } \\
\text { producción tipo "guión". }\end{array}$ & $\begin{array}{l}\text { El análisis se hace sobre } \\
\text { el contenido total del } \\
\text { relato. }\end{array}$ & & & \\
\hline 3 & $\begin{array}{l}\text { Cantidad de } \\
\text { detalles }\end{array}$ & $\begin{array}{l}\text { Se puntúa presente cuando } \\
\text { aparecen elementos como la } \\
\text { descripción del lugar, las } \\
\text { personas o cuando se relatan } \\
\text { sucesión de acontecimientos } \\
\text { paso a paso (Steller, et al, } \\
\text { 1994). }\end{array}$ & $\begin{array}{l}\text { El análisis se hace sobre } \\
\text { el contenido total del } \\
\text { relato. }\end{array}$ & & & \\
\hline
\end{tabular}




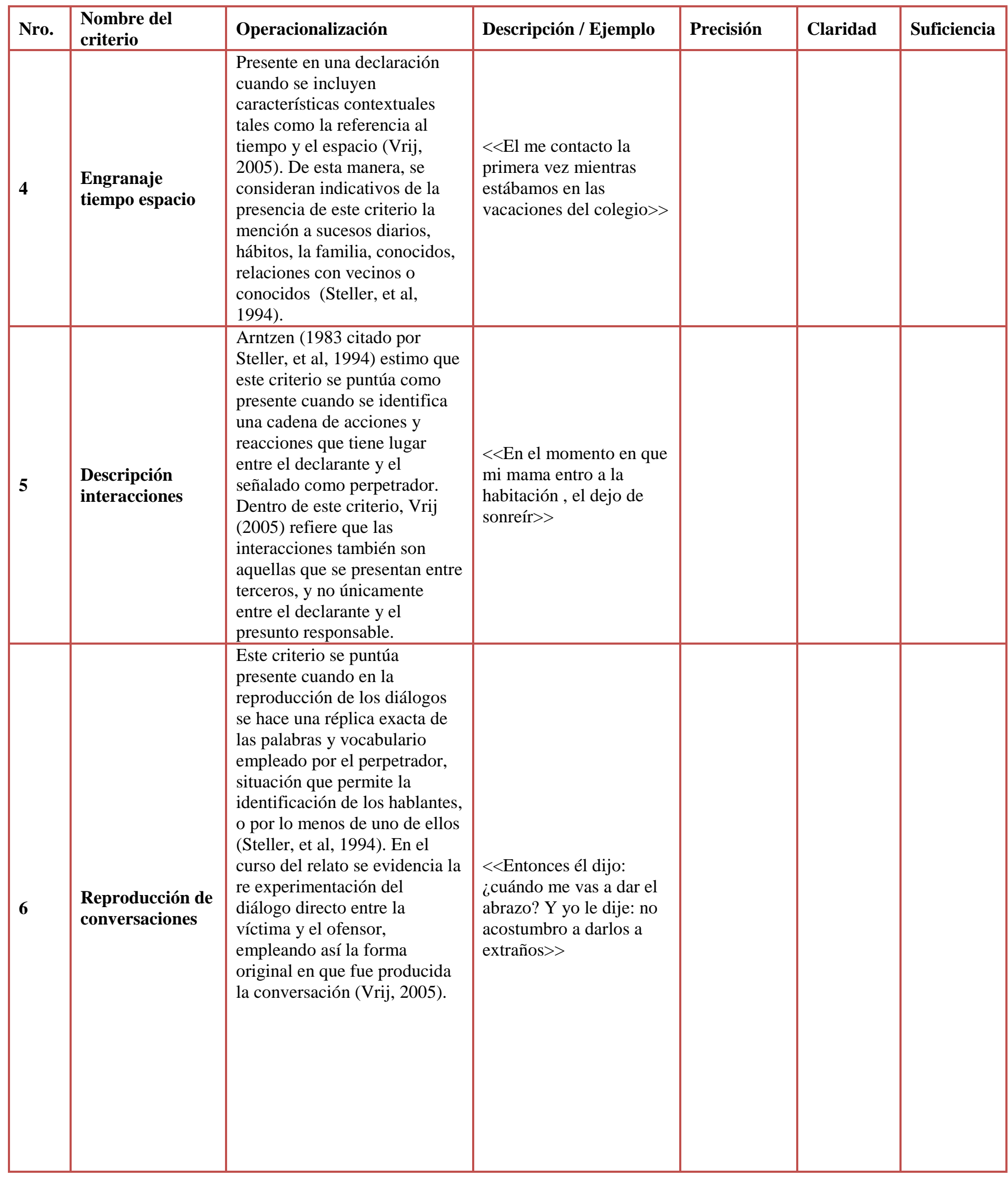




\begin{tabular}{|c|c|c|c|c|c|c|}
\hline Nro. & $\begin{array}{l}\text { Nombre del } \\
\text { criterio }\end{array}$ & Operacionalización & Descripción / Ejemplo & Precisión & Claridad & Suficiencia \\
\hline 7 & $\begin{array}{l}\text { Complicaciones } \\
\text { inesperadas }\end{array}$ & $\begin{array}{l}\text { Este criterio se hace presente } \\
\text { cuando se incorporan } \\
\text { elementos a la declaración que } \\
\text { de alguna forma resultan } \\
\text { inesperados (Vrij, 2005). } \\
\text { Teóricamente se ha propuesto } \\
\text { que estas complicaciones } \\
\text { pueden incluir una } \\
\text { interrupción imprevista o la } \\
\text { dificultad en la finalización } \\
\text { espontanea del suceso previo a } \\
\text { su terminación lógica (Steller, } \\
\text { et al, 1994). }\end{array}$ & $\begin{array}{l}\text { El niño menciona que el } \\
\text { agresor tenía dificultades } \\
\text { para encender su } \\
\text { vehículo. } \\
\text { << Cuando él me estaba } \\
\text { tocando mi hermanita } \\
\text { llego a la casa y el me } \\
\text { bajo rápido de sus } \\
\text { piernas > }\end{array}$ & & & \\
\hline 8 & $\begin{array}{l}\text { Detalles } \\
\text { inusuales }\end{array}$ & $\begin{array}{l}\text { Se puntúa como presente } \\
\text { cuando al interior de la } \\
\text { narración se presentan detalles } \\
\text { que son poco comunes pero } \\
\text { que significativos (Vrij, 2005). } \\
\text { Este criterio hace referencia de } \\
\text { esta forma a la unicidad o a la } \\
\text { baja probabilidad de } \\
\text { ocurrencia. }\end{array}$ & $\begin{array}{l}\text { El testigo que menciona } \\
\text { que el sujeto que conoció } \\
\text { era tartamudo. }\end{array}$ & & & \\
\hline 9 & $\begin{array}{l}\text { Detalles } \\
\text { superfluos }\end{array}$ & $\begin{array}{l}\text { El criterio se puntuara } \\
\text { presente cuando existan dentro } \\
\text { de la narración detalles que no } \\
\text { son esenciales para la } \\
\text { acusación pero que el testigo } \\
\text { presenta o incorpora en asocio } \\
\text { con los eventos denunciados } \\
\text { (Steller, et al, 1994). }\end{array}$ & $\begin{array}{l}\text { El niño que describe que } \\
\text { el perpetrador era } \\
\text { alérgico a los gatos }\end{array}$ & & & \\
\hline 10 & $\begin{array}{l}\text { Incomprensión } \\
\text { de detalles } \\
\text { relatados con } \\
\text { precisión }\end{array}$ & $\begin{array}{l}\text { Se encuentra presente cuando } \\
\text { se relatan acciones o detalles } \\
\text { que el niño no comprende, que } \\
\text { están más allá de su capacidad } \\
\text { interpretativa, pero que el } \\
\text { entrevistador si logra hacerlo } \\
\text { (Steller, et al, 1994; Vrij, } \\
\text { 2005). }\end{array}$ & $\begin{array}{l}\text { Cuando el niño o la niña } \\
\text { describe el } \\
\text { comportamiento sexual } \\
\text { adulto pero se lo atribuye } \\
\text { a un estornudo o al dolor. } \\
<<\text { Y el pene escupió... } \\
\text { le salió un líquido blanco } \\
\text { como leche... }>>\end{array}$ & & & \\
\hline 11 & $\begin{array}{l}\text { Asociaciones } \\
\text { externas } \\
\text { relacionadas }\end{array}$ & $\begin{array}{l}\text { El criterio se encuentra en una } \\
\text { narración si el menor refiere } \\
\text { detalles que no son parte } \\
\text { esencial del incidente pero } \\
\text { están relacionados con el } \\
\text { (Vrij, 2005). Según Arntzen } \\
\text { (1983 citado por Steller, et } \\
\text { al, 1994), el criterio también } \\
\text { está presente en la narración al } \\
\text { relatar conversaciones que } \\
\text { hacen alusión a otros sucesos } \\
\text { que dan cuenta de por lo } \\
\text { menos dos relaciones. }\end{array}$ & $\begin{array}{l}\text { En la narración se } \\
\text { describe que el } \\
\text { perpetrador hablaba de } \\
\text { las personas con las que } \\
\text { el habría sostenido } \\
\text { relaciones sexuales y las } \\
\text { diferencias entre ellas. } \\
\text { Conversaciones en las } \\
\text { que el ofensor pregunto } \\
\text { acerca de la conducta } \\
\text { sexual del menor. }\end{array}$ & & & \\
\hline
\end{tabular}




\begin{tabular}{|c|c|c|c|c|c|c|}
\hline Nro. & $\begin{array}{l}\text { Nombre del } \\
\text { criterio }\end{array}$ & Operacionalización & Descripción / Ejemplo & Precisión & Claridad & Suficiencia \\
\hline 12 & $\begin{array}{l}\text { Relatos del } \\
\text { estado mental } \\
\text { subjetivo }\end{array}$ & $\begin{array}{l}\text { Presente cuando en la } \\
\text { declaración se describen los } \\
\text { sentimientos o pensamientos } \\
\text { experimentados por el menor } \\
\text { al momento de los hechos } \\
\text { (Vrij, 2005). En este sentido, } \\
\text { incluye referencias al miedo o } \\
\text { el asco; así como cogniciones } \\
\text { asociadas al querer escapar de } \\
\text { la situación (Steller, et al, } \\
\text { 1994). }\end{array}$ & $\begin{array}{l}<<\ldots \text { en ese momento } \\
\text { sentí miedo ... al ver eso } \\
\text { me dio asco...estaba } \\
\text { angustiado (a) }>>\end{array}$ & & & \\
\hline 13 & $\begin{array}{l}\text { Atribución del } \\
\text { estado mental } \\
\text { del autor }\end{array}$ & $\begin{array}{l}\text { Hace referencia a los estados } \\
\text { mentales y motivos que el } \\
\text { menor atribuye al } \\
\text { comportamiento del agresor; } \\
\text { así como, las reacciones } \\
\text { afectivas o estados } \\
\text { fisiológicos del perpetrador } \\
\text { citados en la declaración } \\
\text { (Undeutsch, 1967 citado por } \\
\text { Steller, et al, 1994) }\end{array}$ & $\begin{array}{l}<<\text { Él estaba nervioso, sus } \\
\text { manos estaban } \\
\text { temblando > }\end{array}$ & & & \\
\hline 14 & $\begin{array}{l}\text { Correcciones } \\
\text { espontáneas }\end{array}$ & $\begin{array}{l}\text { Se puntúa presente cuando en } \\
\text { la declaración el menor se } \\
\text { corrige a sí mismo de manera } \\
\text { espontánea o brinda nuevas } \\
\text { explicaciones o aclaraciones a } \\
\text { un suceso que puede percibir } \\
\text { que no le fue comprensible al } \\
\text { entrevistador (Steller, et al, } \\
\text { 1994). No se tiene como } \\
\text { presente cuando la corrección } \\
\text { es producto de la intervención } \\
\text { del entrevistador. }\end{array}$ & $\begin{array}{l}<<\text { El vestía una camiseta } \\
\text { negra, no, no, perdón, era } \\
\text { verde >> }\end{array}$ & & & \\
\hline 15 & $\begin{array}{l}\text { Admisión de } \\
\text { falta de memoria }\end{array}$ & $\begin{array}{l}\text { Presente dentro de una } \\
\text { declaración cuando se expresa } \\
\text { preocupación respecto a que } \\
\text { algunas partes de la misma } \\
\text { pueden ser incorrectas. (Vrij, } \\
\text { 2005) }\end{array}$ & $\begin{array}{l}<<\text { yo creo }>>,\langle<\text { tal } \\
\text { vez }>>,\langle<\text { de pronto }>>, \\
<<\text { no estoy seguro, no } \\
\text { recuerdo bien }>>\text { etc. }\end{array}$ & & & \\
\hline 16 & $\begin{array}{l}\text { Dudas sobre el } \\
\text { propio } \\
\text { testimonio }\end{array}$ & $\begin{array}{l}\text { Presente cuando en la } \\
\text { narración se anticipan } \\
\text { objeciones a la calidad de } \\
\text { verdad del propio testimonio } \\
\text { (Vrij, 2005). }\end{array}$ & $\begin{array}{l}\text { <<Yo sé que todo esto } \\
\text { puede sonar bastante } \\
\text { extraño >> }\end{array}$ & & & \\
\hline 17 & $\begin{array}{l}\text { Auto } \\
\text { desaprobación }\end{array}$ & $\begin{array}{l}\text { Se puntúa presente cuando en } \\
\text { la narración se encuentran } \\
\text { detalles auto incriminatorios o } \\
\text { desfavorables que se derivan } \\
\text { de una auto-acusación. } \\
\text { (Undeutsch, 1967 citado por } \\
\text { Steller et al, 1994). }\end{array}$ & $\begin{array}{l}<<\text { Obviamente fue } \\
\text { estúpido de mi parte el ir } \\
\text { a su casa }>><<\text { Fue mi } \\
\text { culpa por haber creído } \\
\text { todo lo que él me } \\
\text { decía }>>\end{array}$ & & & \\
\hline
\end{tabular}


VALIDEZ DE LA TÉCNICA ANÁLISIS DE CONTENIDO BASADO EN

CRITERIOS 67

\begin{tabular}{|c|c|c|c|c|c|c|}
\hline Nro. & $\begin{array}{l}\text { Nombre del } \\
\text { criterio }\end{array}$ & Operacionalización & Descripción / Ejemplo & Precisión & Claridad & Suficiencia \\
\hline 18 & $\begin{array}{l}\text { Perdón al } \\
\text { agresor }\end{array}$ & $\begin{array}{l}\text { Está presente cuando en la } \\
\text { declaración se tiene a } \\
\text { favorecer o justificar al } \\
\text { perpetrador (Steller y } \\
\text { Koehnken, 1994). En adición, } \\
\text { Vrij (2005) refiere que el } \\
\text { criterio se puntúa como } \\
\text { presente cuando hay un fallo } \\
\text { en la atribución de la } \\
\text { responsabilidad que sobre la } \\
\text { conducta del agresor debe } \\
\text { recaer. }\end{array}$ & $\begin{array}{l}\text { La victima menciona que } \\
\text { ahora siente pena, } \\
\text { lastima, tristeza o } \\
\text { empatía por la } \\
\text { posibilidad que el } \\
\text { agresor sea enviado a la } \\
\text { cárcel. }\end{array}$ & & & \\
\hline 19 & $\begin{array}{l}\text { Detalles } \\
\text { característicos de } \\
\text { la ofensa }\end{array}$ & $\begin{array}{l}\text { Se encuentra al interior de una } \\
\text { narración si la descripción del } \\
\text { evento es típica o común para } \\
\text { el tipo de delito que se está } \\
\text { indagando (Vrij, 2005) }\end{array}$ & $\begin{array}{l}\text { El análisis se hace sobre } \\
\text { el contenido total del } \\
\text { relato. }\end{array}$ & & & \\
\hline
\end{tabular}

Observaciones: 
Apéndice B.

Concordancia entre Jueces para los 19 Criterios de la Técnica CBCA

\begin{tabular}{|c|c|c|c|c|c|c|}
\hline CBCA & $\begin{array}{c}\text { S1- } \\
\text { J1 }\end{array}$ & $\begin{array}{l}\text { S1- } \\
\text { J2 }\end{array}$ & $\begin{array}{l}\text { S1- } \\
\text { J3 }\end{array}$ & A1 & S1 & P1 \\
\hline CBCA1 & 1 & 1 & 1 & 1 & 1 & 1,00 \\
\hline CBCA2 & 1 & 0 & 1 & 0 & 1 & 0,67 \\
\hline СВCA3 & 1 & 0 & 1 & 0 & 1 & 0,67 \\
\hline CBCA4 & 1 & 1 & 1 & 1 & 1 & 1,00 \\
\hline CBCA5 & 1 & 1 & 1 & 1 & 1 & 1,00 \\
\hline CBCA6 & 1 & 1 & 1 & 1 & 1 & 1,00 \\
\hline CBCA7 & 1 & 0 & 0 & 0 & 0 & 0,33 \\
\hline CBCA8 & 0 & 0 & 0 & 1 & 0 & 0,00 \\
\hline CBCA9 & 1 & 1 & 1 & 1 & 1 & 1,00 \\
\hline CBCA10 & 0 & 0 & 0 & 1 & 0 & 0,00 \\
\hline CBCA11 & 1 & 0 & 1 & 0 & 1 & 0,67 \\
\hline CBCA12 & 1 & 0 & 1 & 0 & 1 & 0,67 \\
\hline CBCA13 & 1 & 1 & 1 & 1 & 1 & 1,00 \\
\hline CBCA14 & 0 & 0 & 0 & 1 & 0 & 0,00 \\
\hline CBCA15 & 1 & 0 & 1 & 0 & 1 & 0,67 \\
\hline CBCA16 & 0 & 0 & 0 & 1 & 0 & 0,00 \\
\hline CBCA17 & 1 & 1 & 1 & 1 & 1 & 1,00 \\
\hline CBCA18 & 0 & 0 & 0 & 1 & 0 & 0,00 \\
\hline CBCA19 & 1 & 1 & 1 & 1 & 1 & 1,00 \\
\hline
\end{tabular}

\begin{tabular}{|l|ccc|ccc|}
\hline CBCA & S2- & S2- & S2- & & & \\
CBCA1 & 1 & 1 & 1 & 1 & 1 & 1,00 \\
CBCA2 & 0 & 0 & 0 & 1 & 0 & 0,00 \\
CBCA3 & 0 & 0 & 0 & 1 & 0 & 0,00 \\
CBCA4 & 1 & 1 & 1 & 1 & 1 & 1,00 \\
CBCA5 & 1 & 1 & 1 & 1 & 1 & 1,00 \\
CBCA6 & 1 & 1 & 0 & 0 & 1 & 0,67 \\
CBCA7 & 1 & 0 & 1 & 0 & 1 & 0,67 \\
CBCA8 & 0 & 0 & 0 & 1 & 0 & 0,00 \\
CBCA9 & 0 & 0 & 0 & 1 & 0 & 0,00 \\
CBCA10 & 0 & 0 & 0 & 1 & 0 & 0,00 \\
CBCA11 & 0 & 0 & 0 & 1 & 0 & 0,00 \\
CBCA12 & 1 & 1 & 1 & 1 & 1 & 1,00 \\
CBCA13 & 1 & 0 & 1 & 0 & 1 & 0,67 \\
CBCA14 & 0 & 0 & 0 & 1 & 0 & 0,00 \\
CBCA15 & 1 & 0 & 1 & 0 & 1 & 0,67 \\
CBCA16 & 0 & 0 & 0 & 1 & 0 & 0,00 \\
CBCA17 & 0 & 0 & 0 & 1 & 0 & 0,00 \\
CBCA18 & 0 & 0 & 0 & 1 & 0 & 0,00 \\
CBCA19 & 1 & 1 & 1 & 1 & 1 & 1,00 \\
\hline
\end{tabular}




\begin{tabular}{|c|c|c|c|c|c|c|}
\hline CBCA & $\begin{array}{l}\text { S3- } \\
\text { J1 }\end{array}$ & $\begin{array}{l}\text { S3- } \\
\text { J2 }\end{array}$ & $\begin{array}{l}\text { S3- } \\
\text { J3 }\end{array}$ & A3 & S3 & P3 \\
\hline CBCA1 & 1 & 1 & 1 & 1 & 1 & 1,00 \\
\hline CBCA2 & 1 & 1 & 1 & 1 & 1 & 1,00 \\
\hline CBCA3 & 1 & 1 & 1 & 1 & 1 & 1,00 \\
\hline CBCA4 & 1 & 1 & 1 & 1 & 1 & 1,00 \\
\hline CBCA5 & 1 & 1 & 1 & 1 & 1 & 1,00 \\
\hline CBCA6 & 1 & 1 & 1 & 1 & 1 & 1,00 \\
\hline CBCA7 & 0 & 0 & 0 & 1 & 0 & 0,00 \\
\hline CBCA8 & 1 & 0 & 0 & 0 & 0 & 0,33 \\
\hline CBCA9 & 1 & 1 & 1 & 1 & 1 & 1,00 \\
\hline CBCA10 & 0 & 0 & 0 & 1 & 0 & 0,00 \\
\hline CBCA11 & 1 & 0 & 1 & 0 & 1 & 0,67 \\
\hline CBCA12 & 1 & 1 & 1 & 1 & 1 & 1,00 \\
\hline CBCA13 & 0 & 0 & 0 & 1 & 0 & 0,00 \\
\hline CBCA14 & 0 & 1 & 0 & 0 & 0 & 0,33 \\
\hline CBCA15 & 1 & 1 & 1 & 1 & 1 & 1,00 \\
\hline CBCA16 & 0 & 0 & 0 & 1 & 0 & 0,00 \\
\hline CBCA17 & 1 & 0 & 1 & 0 & 1 & 0,67 \\
\hline CBCA18 & 1 & 0 & 0 & 0 & 0 & 0,33 \\
\hline CBCA19 & 1 & 1 & 1 & 1 & 1 & 1,00 \\
\hline
\end{tabular}

\begin{tabular}{|c|c|c|c|c|c|c|}
\hline CBCA & $\begin{array}{l}\text { S4- } \\
\text { J1 }\end{array}$ & $\begin{array}{l}\text { S4- } \\
\text { J2 }\end{array}$ & $\begin{array}{l}\text { S4- } \\
\text { J3 }\end{array}$ & A4 & S4 & P4 \\
\hline CBCA1 & 1 & 1 & 1 & 1 & 1 & 1,00 \\
\hline CBCA2 & 1 & 1 & 1 & 1 & 1 & 1,00 \\
\hline CBCA3 & 1 & 1 & 1 & 1 & 1 & 1,00 \\
\hline CBCA4 & 1 & 1 & 1 & 1 & 1 & 1,00 \\
\hline CBCA5 & 1 & 1 & 1 & 1 & 1 & 1,00 \\
\hline CBCA6 & 1 & 1 & 1 & 1 & 1 & 1,00 \\
\hline CBCA7 & 1 & 1 & 1 & 1 & 1 & 1,00 \\
\hline CBCA8 & 0 & 0 & 0 & 1 & 0 & 0,00 \\
\hline CBCA9 & 1 & 1 & 1 & 1 & 1 & 1,00 \\
\hline CBCA10 & 0 & 0 & 0 & 1 & 0 & 0,00 \\
\hline CBCA11 & 0 & 0 & 0 & 1 & 0 & 0,00 \\
\hline CBCA12 & 1 & 0 & 1 & 0 & 1 & 0,67 \\
\hline CBCA13 & 0 & 0 & 0 & 1 & 0 & 0,00 \\
\hline CBCA14 & 0 & 0 & 1 & 0 & 0 & 0,33 \\
\hline CBCA15 & 1 & 1 & 1 & 1 & 1 & 1,00 \\
\hline CBCA16 & 0 & 0 & 0 & 1 & 0 & 0,00 \\
\hline CBCA17 & 0 & 0 & 0 & 1 & 0 & 0,00 \\
\hline CBCA18 & 0 & 0 & 0 & 1 & 0 & 0,00 \\
\hline CBCA19 & 1 & 1 & 1 & 1 & 1 & 1,00 \\
\hline
\end{tabular}




\begin{tabular}{|c|c|c|c|c|c|c|}
\hline CBCA & $\begin{array}{c}\text { S5- } \\
\text { J1 }\end{array}$ & $\begin{array}{c}\text { S5- } \\
\text { J2 }\end{array}$ & $\begin{array}{c}\text { S5- } \\
\text { J3 }\end{array}$ & A5 & S5 & P5 \\
\hline CBCA1 & 1 & 1 & 1 & 1 & 1 & 1,00 \\
\hline CBCA2 & 1 & 1 & 1 & 1 & 1 & 1,00 \\
\hline CBCA3 & 1 & 1 & 1 & 1 & 1 & 1,00 \\
\hline CBCA4 & 1 & 1 & 1 & 1 & 1 & 1,00 \\
\hline CBCA5 & 1 & 1 & 1 & 1 & 1 & 1,00 \\
\hline CBCA6 & 1 & 1 & 1 & 1 & 1 & 1,00 \\
\hline CBCA7 & 0 & 0 & 0 & 1 & 0 & 0,00 \\
\hline CBCA8 & 0 & 0 & 0 & 1 & 0 & 0,00 \\
\hline CBCA9 & 1 & 1 & 1 & 1 & 1 & 1,00 \\
\hline CBCA10 & 1 & 1 & 1 & 1 & 1 & 1,00 \\
\hline CBCA11 & 1 & 1 & 1 & 1 & 1 & 1,00 \\
\hline CBCA12 & 1 & 1 & 1 & 1 & 1 & 1,00 \\
\hline CBCA13 & 1 & 0 & 0 & 0 & 0 & 0,33 \\
\hline CBCA14 & 1 & 1 & 1 & 1 & 1 & 1,00 \\
\hline CBCA15 & 1 & 1 & 1 & 1 & 1 & 1,00 \\
\hline CBCA16 & 0 & 0 & 0 & 0 & 0 & 0,00 \\
\hline CBCA17 & 0 & 0 & 0 & 0 & 0 & 0,00 \\
\hline CBCA18 & 0 & 0 & 0 & 0 & 0 & 0,00 \\
\hline CBCA19 & 1 & 1 & 1 & 1 & 1 & 1,00 \\
\hline
\end{tabular}

\begin{tabular}{|c|c|c|c|c|c|c|}
\hline CBCA & $\begin{array}{l}\text { S6- } \\
\text { J1 }\end{array}$ & $\begin{array}{l}\text { S6- } \\
\text { J2 }\end{array}$ & $\begin{array}{l}\text { S6- } \\
\text { J3 }\end{array}$ & A6 & S6 & P6 \\
\hline CBCA1 & 1 & 1 & 1 & 1 & 1 & 1,00 \\
\hline CBCA2 & 1 & 0 & 1 & 0 & 1 & 0,67 \\
\hline СВСАЗ & 1 & 1 & 1 & 1 & 1 & 1,00 \\
\hline CBCA4 & 1 & 1 & 1 & 1 & 1 & 1,00 \\
\hline CBCA5 & 1 & 1 & 1 & 1 & 1 & 1,00 \\
\hline CBCA6 & 1 & 1 & 1 & 1 & 1 & 1,00 \\
\hline CBCA7 & 0 & 0 & 0 & 1 & 0 & 0,00 \\
\hline CBCA8 & 0 & 1 & 0 & 0 & 0 & 0,33 \\
\hline CBCA9 & 1 & 0 & 1 & 0 & 1 & 0,67 \\
\hline CBCA10 & 1 & 0 & 1 & 0 & 1 & 0,67 \\
\hline CBCA11 & 0 & 0 & 0 & 1 & 0 & 0,00 \\
\hline CBCA12 & 1 & 0 & 1 & 0 & 1 & 0,67 \\
\hline CBCA13 & 0 & 0 & 0 & 1 & 0 & 0,00 \\
\hline CBCA14 & 1 & 0 & 0 & 0 & 0 & 0,33 \\
\hline CBCA15 & 1 & 1 & 1 & 1 & 1 & 1,00 \\
\hline CBCA16 & 0 & 0 & 0 & 1 & 0 & 0,00 \\
\hline CBCA17 & 0 & 0 & 0 & 1 & 0 & 0,00 \\
\hline CBCA18 & 0 & 0 & 0 & 1 & 0 & 0,00 \\
\hline CBCA19 & 1 & 1 & 1 & 1 & 1 & 1,00 \\
\hline
\end{tabular}




\begin{tabular}{|c|c|c|c|c|c|c|}
\hline CBCA & $\begin{array}{l}\text { S7- } \\
\text { J1 }\end{array}$ & $\begin{array}{l}\text { S7- } \\
\text { J2 }\end{array}$ & $\begin{array}{c}\text { S7- } \\
\text { J3 }\end{array}$ & A7 & S7 & P7 \\
\hline CBCA1 & 1 & 1 & 1 & 1 & 1 & 1,00 \\
\hline CBCA2 & 1 & 0 & 1 & 0 & 1 & 0,67 \\
\hline CBCA3 & 1 & 1 & 1 & 1 & 1 & 1,00 \\
\hline CBCA4 & 1 & 1 & 1 & 1 & 1 & 1,00 \\
\hline CBCA5 & 1 & 1 & 1 & 1 & 1 & 1,00 \\
\hline CBCA6 & 1 & 1 & 1 & 1 & 1 & 1,00 \\
\hline CBCA7 & 0 & 0 & 0 & 1 & 0 & 0,00 \\
\hline CBCA8 & 0 & 0 & 0 & 1 & 0 & 0,00 \\
\hline CBCA9 & 1 & 0 & 1 & 0 & 1 & 0,67 \\
\hline CBCA10 & 1 & 0 & 1 & 0 & 1 & 0,67 \\
\hline CBCA11 & 1 & 0 & 1 & 0 & 1 & 0,67 \\
\hline CBCA12 & 1 & 1 & 1 & 1 & 1 & 1,00 \\
\hline CBCA13 & 1 & 0 & 1 & 0 & 1 & 0,67 \\
\hline CBCA14 & 0 & 0 & 0 & 1 & 0 & 0,00 \\
\hline CBCA15 & 1 & 0 & 1 & 0 & 1 & 0,67 \\
\hline CBCA16 & 0 & 0 & 0 & 1 & 0 & 0,00 \\
\hline CBCA17 & 0 & 0 & 0 & 1 & 0 & 0,00 \\
\hline CBCA18 & 0 & 0 & 0 & 1 & 0 & 0,00 \\
\hline CBCA19 & 1 & 1 & 1 & 1 & 1 & 1,00 \\
\hline
\end{tabular}

\begin{tabular}{|c|c|c|c|c|c|c|}
\hline CBCA & $\begin{array}{l}\text { S8- } \\
\text { J1 }\end{array}$ & $\begin{array}{l}\text { S8- } \\
\text { J2 }\end{array}$ & $\begin{array}{l}\text { S8- } \\
\text { J3 }\end{array}$ & A8 & S8 & P8 \\
\hline CBCA1 & 1 & 1 & 1 & 1 & 1 & 1,00 \\
\hline CBCA2 & 1 & 1 & 1 & 1 & 1 & 1,00 \\
\hline СВСАЗ & 1 & 1 & 1 & 1 & 1 & 1,00 \\
\hline CBCA4 & 1 & 1 & 1 & 1 & 1 & 1,00 \\
\hline CBCA5 & 1 & 1 & 1 & 1 & 1 & 1,00 \\
\hline CBCA6 & 1 & 1 & 1 & 1 & 1 & 1,00 \\
\hline CBCA7 & 1 & 0 & 1 & 0 & 1 & 0,67 \\
\hline CBCA8 & 1 & 0 & 1 & 0 & 1 & 0,67 \\
\hline CBCA9 & 1 & 0 & 0 & 0 & 0 & 0,33 \\
\hline CBCA10 & 0 & 0 & 0 & 1 & 0 & 0,00 \\
\hline CBCA11 & 1 & 1 & 1 & 1 & 1 & 1,00 \\
\hline CBCA12 & 1 & 1 & 1 & 1 & 1 & 1,00 \\
\hline CBCA13 & 1 & 1 & 1 & 1 & 1 & 1,00 \\
\hline CBCA14 & 0 & 1 & 0 & 0 & 0 & 0,33 \\
\hline CBCA15 & 1 & 0 & 1 & 0 & 1 & 0,67 \\
\hline CBCA16 & 0 & 0 & 0 & 1 & 0 & 0,00 \\
\hline CBCA17 & 1 & 1 & 1 & 1 & 1 & 1,00 \\
\hline CBCA18 & 0 & 0 & 0 & 1 & 0 & 0,00 \\
\hline CBCA19 & 1 & 1 & 1 & 1 & 1 & 1,00 \\
\hline
\end{tabular}

